Research Article

\title{
Earthquake Response Analysis of Tall Reinforced Concrete Chimneys considering Eccentricity
}

\author{
Yingchun Jiang $D^{1},{ }^{1}$ Tielin Liu, ${ }^{2}$ and Yikui Bai ${ }^{3}$ \\ ${ }^{1}$ College of Engineering, Shenyang Agricultural University, Shenyang 110866, China \\ ${ }^{2}$ School of Civil Engineering, Shenyang Jianzhu University, Shenyang 110168, China \\ ${ }^{3}$ College of Water Conservancy, Shenyang Agricultural University, Shenyang 110866, China \\ Correspondence should be addressed to Yingchun Jiang; jyclg@syau.edu.cn
}

Received 14 October 2019; Revised 7 January 2020; Accepted 29 January 2020; Published 11 March 2020

Academic Editor: Salvatore Caddemi

Copyright (c) 2020 Yingchun Jiang et al. This is an open access article distributed under the Creative Commons Attribution License, which permits unrestricted use, distribution, and reproduction in any medium, provided the original work is properly cited.

\begin{abstract}
A numerical algorithm is presented to analyze earthquake response of tall reinforced concrete (RC) chimneys based on stick multidegree-of-freedom models. The algorithm considers the eccentricity phenomena between spatial discrete nodes and corresponding centroids of investigated lumps. The spatial discrete segments of the chimney are used to construct the investigated lumps. The equations of dynamic equilibrium of the investigated lumps are derived, and the numerical calculation procedure is implemented. Phenomena of eccentricity are studied for $150 \mathrm{~m}$ and $210 \mathrm{~m} \mathrm{RC}$ chimneys. Seismic stresses and effects of vertical ground motion for the two chimneys are also studied. Numerical results show that the tensile and compressive stresses of the seismic control cross sections of the chimneys may increase under the actions of several specific earthquake waves by considering existing eccentricities. The effect of eccentricity on the earthquake responses of tall RC chimney should be considered, and stresses caused by vertical ground motion should not be neglected to obtain accurate earthquake response of chimneys.
\end{abstract}

\section{Introduction}

1.1. Literature Review. Many tall reinforced concrete (RC) chimneys have been built in places such as coal-fired power stations and refinery because of the requirements of air pollution control standards. Slender tall chimneys are sensitive to earthquake. Strong earthquake threatens the safety of the chimney and other buildings around it because of the nonuniformity of the diameter along the height of the chimney and the variation in dead weights at different heights. Research and calculations of earthquake response are necessary for the designs of tall RC chimneys under the action of earthquakes.

Destruction and collapse of tall chimneys bring huge economic losses. Research on seismic damage of chimneys indicates that the destructive effect of vertical earthquake on chimneys should be considered [1]. Liu and He [2] analyzed the seismic response of a chimney under the action of combined horizontal and vertical ground motions. They concluded that vertical stress cannot be neglected completely although horizontal seismic stress is the controlling part. Wang and Liao [3] developed a calculation technique for analyzing the vertical earthquake response of a chimney based on multiple reflections of traveling waves in the chimney. Liu et al. [4] conducted earthquake transient response of multidegree-of-freedom (MDOF) systems by the model superposition method. Ding et al. [5] conducted a vertical impact to the bottoms of chimney models. The test results showed that only one circle crack appeared in the chimney models, and the crack had relations with the ratio of input wave frequency to the natural frequency of the chimney model. Chen et al. [6] used a shaking table to study the fracture phenomenon of a chimney under the action of vertical earthquake. They found that vertical seismic action should be considered in the structural design of chimneys.

A 115 m high RC chimney collapsed on August 17, 1999, during the Izmit earthquake in Turkey [7-10]. Huang et al. $[7,8]$ investigated a collapsed chimney with methods of 
linear dynamic response spectrum and nonlinear static capacity spectrum. Akinci [9] used shell elements to analyze a collapsed chimney. The analysis results indicated that low ductility and inadequate capacity due to a large duct were the two significant factors for the collapsed chimney. Huang and Gould [10] further proposed a new three-dimensional (3-D) pushover analysis method to study the dynamic response of the stack due to an earthquake motion recorded at a nearby site. Lopes et al. [11] constructed a realistic numerical model to evaluate the seismic vulnerability of a chimney and simulated its damaged state. Minghini et al. [12] analyzed a brickwork chimney and a shear failure mechanism of the upper part of the chimney damaged by the 2012 Emilia earthquake. Zhou et al. selected an existing $240 \mathrm{~m}$ tall RC chimney as the research object and analyzed the seismic vulnerability curve of the chimney by considering structural damage [13], structural nonlinearity [14], and multidimensional earthquake [15] and evaluated and analyzed the vulnerability of the chimney structure.

The modal frequency and mode shape are the main dynamic characteristics of chimneys. Chen et al. [16] used the Adomian decomposition method to decompose dimensionless modal shape and calculated the dynamic characteristics of a high-rise chimney. Sancibrian et al. [17] used the continuum structure system to analyze the dynamic characteristics of a chimney, including natural frequencies and mode shapes. Tatara and Ratajewicz [18] evaluated the dynamic characteristics of a typical RC industrial chimney that belongs to a heating plant and determined the lowest vibration frequency of the structure.

Soil-structure interaction (SSI) has a great influence on the seismic performance of tall chimney structures $[19,20]$. Halabian and Kabiri [21] studied the effect of foundation stiffness of different types of RC chimneys on the ductility reduction coefficient. A series of inelastic and elastic time history analyses up to the collapse status for a large variety of RC chimneys subjected to five scaled artificial records were conducted. Jisha et al. [22] analyzed 3-D SSI of tall RC chimneys with annular raft foundation and evaluated the effect of SSI by changing the stiffness of supporting soil and foundation [23]. Zhou et al. [24, 25] studied the effect of SSI on the seismic collapse resistance of chimney structure for a $240 \mathrm{~m}$ high RC chimney.

Time period is an important approach of evaluating the structural response of a structure subjected to large-scale earthquake vibrations. The seismic response of chimney structures uses time history analysis considering earthquake, which is a long-duration earthquake impulse [19]. Sarkar et al. [26] studied the effects of different base conditions on the design value of shear force and bending moment of different sections of a $275 \mathrm{~m}$ tall RCC multiflue chimney by using a response spectrum method. The spectrum compatibility time history of specific engineering site was considered, and the time history dynamic analysis of the chimney structure was conducted in detail. Wilson [27] studied the inelastic response of 10 RC chimneys ranging from $115 \mathrm{~m}$ to $301 \mathrm{~m}$ subject to earthquake excitation. Liu et al. [28] studied the structural dynamic performance and elastic-plastic seismic response of a $240 \mathrm{~m}$ high special- shaped RC chimney. The weak position of the chimney was discussed by analyzing its interlayer displacement angle.

1.2. Motivation. When the stick MDOF structural model is used to study the dynamic response of tall chimney structures, the chimney structure is usually discretized into beam elements of a certain length. Thin beam elements are good, but they are not sufficiently thin in practical analysis. The cross section area of a chimney structure is variable at different heights. Therefore, even if the discrete length of space is equal, the vertical eccentricity of mass will occur because the mass of each element will be uneven. The vertical eccentricity of mass must be considered to improve the accuracy and validity of dynamic response analysis.

A numerical algorithm is presented in this study to analyze the earthquake response of tall RC chimneys. The chimney is spatially discretized into several segments of finite length, and the investigated lumps are then constructed by using these segments. The calculating formulae of axial force, shear force, and bending moment acting on the median cross section of each segment are derived. These interior forces are associated with end displacement and angle. Not only the inertial forces of the investigated lumps are considered but also the rotary inertias of investigated lumps. Existing eccentricity phenomena between spatial discrete nodes and corresponding centroids of investigated lumps are considered. Dynamic equations and relations are applied alternately in the time domain to calculate the seismic response of the chimney. Two RC chimneys of $150 \mathrm{~m}$ and $210 \mathrm{~m}$ height are studied. The numerical results show that the effects of such eccentricities on earthquake response should not be neglected for tall chimneys, as well as the vertical ground motion.

\section{Numerical Algorithm}

2.1. Governing Equations of Investigated Lumps. A chimney with variable cross section can be discretized into many segments of different cross section areas along the vertical direction in practical calculation based on the stick MDOF model. These segments are used to construct the investigated lumps. Figure 1 shows a typical investigated lump $i$ (the nodal numbering $i$ is also used to describe the investigated lump) consisting of half the upper segment and half the lower segment around the discrete node $i$. Sign $C$ is the centroid of the investigated lump. The centroid of the investigated lump is commonly not at the same point of the corresponding discrete node $i$ for the chimney with variable cross-sectional area. Here, the distance between the discrete node and the centroid of the investigated lump within the same investigated lump is called eccentricity.

The vertical equilibrium equation for the centroid of investigated lump $i$ is

$$
m_{i} \ddot{w}_{c i}=N_{l-1}-N_{l}-m_{i} g,
$$

where $m_{i}$ is the mass of investigated lump $i, \ddot{w}_{c i}$ is the vertical acceleration of centroid $C$, and $N_{l-1}$ and $N_{l}$ are the axial forces acting on investigated lump $i$. 


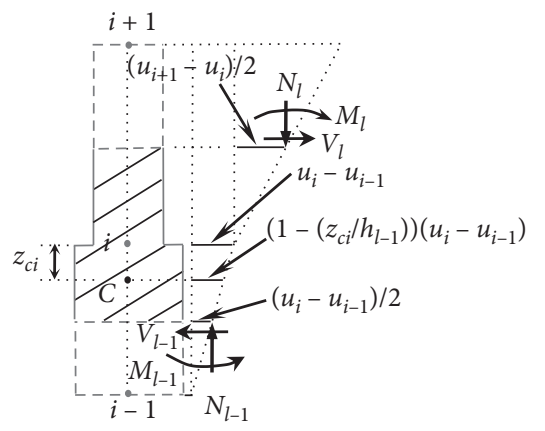

FIGURE 1: Sketch of deformation of investigated lump $i$.

The transverse equilibrium equation for the centroid of investigated lump $i$ is

$$
m_{i} \ddot{u}_{c i}=V_{l}-V_{l-1},
$$

where $\ddot{u}_{c i}$ is the horizontal acceleration of the centroid of investigated lump $i$ and $V_{l}$ and $V_{l-1}$ are the shear forces acting on investigated lump $i$.

On the basis of mechanics theory, the rotational equilibrium equation should be established about the horizontal axis ( $y$-axis) through centroid $C$ of investigated lump $i$, that is,

$$
J_{c i} \ddot{\theta}_{i}=\left(M_{l}-M_{l-1}\right)+V_{l}\left(\frac{h_{l}}{2}+z_{c i}\right)+V_{l-1}\left(\frac{h_{l-1}}{2}-z_{c i}\right)+N_{l}\left[\frac{u_{i+1}-u_{i}}{2}+\frac{z_{c i}\left(u_{i}-u_{i-1}\right)}{h_{l-1}}\right]+N_{l-1}\left(\frac{1}{2}-\frac{z_{c i}}{h_{l-1}}\right)\left(u_{i}-u_{i-1}\right),
$$

$$
\begin{aligned}
N_{i+1}^{\prime} & =N_{i}^{\prime}=\frac{(\mathrm{EA})_{l}}{h_{l}}\left(w_{i}-w_{i+1}\right), \\
V_{i+1}^{\prime} & =-V_{i}^{\prime}=K_{1 l}\left(u_{i+1}-u_{i}\right)+K_{2 l}\left(\theta_{i}+\theta_{i+1}\right), \\
M_{i}^{\prime} & =K_{2 l}\left(u_{i+1}-u_{i}\right)+K_{3 l} \theta_{i}+K_{4 l} \theta_{i+1}, \\
M_{i+1}^{\prime} & =K_{2 l}\left(u_{i+1}-u_{i}\right)+K_{4 l} \theta_{i}+K_{3 l} \theta_{i+1},
\end{aligned}
$$

where $K_{1 l}=\left(12(\mathrm{EI})_{l} / h_{l}^{3}\left(1+2 \alpha_{l}\right)\right)-\left(6 N_{l} / 5 h_{l}\right), \quad K_{2 l}=-(6$ $\left.(\mathrm{EI})_{l} / h_{l}^{2}\left(1+2 \alpha_{l}\right)\right)+\left(N_{l} / 10\right), K_{3 l}=\left(4\left(1+0.5 \alpha_{l}\right)(\mathrm{EI})_{l} / h_{l}(1+\right.$ $\left.\left.2 \alpha_{l}\right)\right)-\left(2 N_{l} h_{l} / 15\right)$, and $K_{4 l}=\left(2\left(1-\alpha_{l}\right)(\mathrm{EI})_{l} / h_{l}\left(1+2 \alpha_{l}\right)\right)+$ $\left(N_{l} h_{l} / 30\right)$. Subscript $l$ denotes the $l^{\text {th }}$ segment. $\alpha_{l}=$ $6(\mathrm{EI})_{l} /\left[h_{l}^{2}(\mathrm{GA})_{l}\right]$ is the coefficient of shear deformation in the transverse direction. $(\mathrm{EI})_{l},(\mathrm{GA})_{l}$, and $(\mathrm{EA})_{l}$ are the bending stiffness, shear stiffness, and tensile/compressive stiffness of segment $l$, respectively. $N_{l}=N_{i g}+N_{i}^{\prime}$, where $N_{i g}$ is the axial force coming from the dead weight of the chimney above node $i . A_{l}$ is the cross-sectional area of segment $l . w_{i}$ and $\theta_{i}$ are the vertical displacement and rotational angle of node $i$, respectively. $w_{i+1}$ and $\theta_{i+1}$ are the vertical displacement and rotational angle of node $i+1$, respectively.

Subtracting equation (8) from equation (7) yields

$$
M_{i}^{\prime}-M_{i+1}^{\prime}=\left[\frac{2(E I)_{l}}{h_{l}}-\frac{N_{l} h_{l}}{6}\right]\left(\theta_{i}-\theta_{i+1}\right) .
$$

Following the beam theory considering shear defor-

mation and axial force, we have

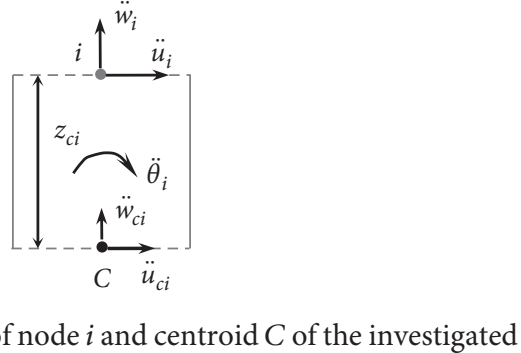

lump.

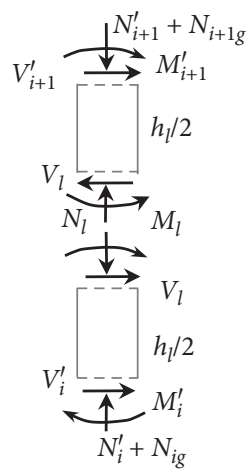

2.2. Forces and Bending Moment on the Central Cross Secti axial compressive forces at the bottom and top segment $l$, respectively, because of its vertical deformation; $V_{i}^{\prime}$ and $V_{i+1}^{\prime}$ are the shear forces; $M_{i}^{\prime}$ and $M_{i+1}^{\prime}$ are the bending moments; $N_{i g}$ is the axial force coming from the dead load of the structure above node $i$; and $N_{i+1 g}$ is the dead load above node $i+1$. 
Given the equilibrium of the upper half of segment $l$, we have

$$
\begin{aligned}
M_{i+1}^{\prime} & =M_{l}-V_{l} \frac{h_{l}}{2}-N_{l} \frac{u_{i+1}-u_{i}}{2}, \\
V_{l} & =K_{1 l}\left(u_{i+1}-u_{i}\right)+K_{2 l}\left(\theta_{i}+\theta_{i+1}\right) .
\end{aligned}
$$

Given the equilibrium of the lower half of segment $l$, we have

$$
M_{i}^{\prime}=-M_{l}-V_{l} \frac{h_{l}}{2}-N_{l} \frac{u_{i+1}-u_{i}}{2},
$$

where $N_{l}, V_{l}$, and $M_{l}$ are the central axial force, central shear force, and central bending moment acting on the central section of segment $l$, respectively.

We substitute equations (10) and (12) into equation (9), and we obtain the central bending moment of segment $l$, shown as follows:

$$
M_{l}=K_{5 l}\left(\theta_{i+1}-\theta_{i}\right),
$$

where $K_{5 l}=\left((\mathrm{EI})_{l} / h_{l}\right)-\left(N_{l} h_{l} / 12\right)$.

2.3. Implementation of Algorithm. Horizontal and vertical earthquake waves are inputted from the foundation of the tall RC chimney. The algorithm description diagram is shown in Figure 4, and the calculating procedure is as follows.

Step 1. Calculate the angular acceleration $\ddot{\theta}_{i}$ of investigated lump $i$ at time $t$ using equation (3), the vertical acceleration $\ddot{w}_{c i}$ at time $t$ using equation (1), $\ddot{w}_{i}$ at time $t$ by considering $\ddot{w}_{i}$ being nearly equal to $\ddot{w}_{c i}$, the horizontal acceleration $\ddot{u}_{c i}$ at time $t$ using equation (2), and $\ddot{u}_{i}$ using equation (4).

Step 2. Calculate angle $\theta_{i}$, vertical displacement $w_{i}$, and horizontal displacement $u_{i}$ for investigated lump $i$ at time $t+\Delta t$ by integration in the time domain.

Step 3. Calculate axial force $N_{i}^{\prime}$ at time $t+\Delta t$ using equation (5) and then obtain central axial force $N_{l}$ using the formula $N_{l}=N_{i g}+N_{i}^{\prime}$. Central shear force $V_{l}$ and central bending moment $M_{l}$ are calculated using equations (11) and (13), respectively, at time $t+\Delta t$.

Step 4. Calculate $\ddot{\theta}_{i}, \ddot{w}_{c i}$, and $\ddot{u}_{c i}$ at time $t+\Delta t$ as performed in Step 1.

The circulation from Step 1 to Step 4 is implemented in the time domain by a computer program. The numerical algorithm is provided to calculate the earthquake response of the tall RC chimney, considering eccentricities $z_{c i}$ $(i=1,2, \ldots, n)$.

Wilson $\theta$ method is used to solve the conventional dynamic equations of equilibrium in which eccentricities are not considered. Their results are called the conventional results in this study.

Here, the rotation of the foundation is not considered.

\section{Stability Condition}

3.1. Corresponding Relations. For simplicity in deriving the stability condition of the algorithm, we assume that $(\mathrm{EI})_{l}=(\mathrm{EI}), h_{l}=h$, and $\alpha_{l}=\alpha$ for all segments. Axial force $N_{l}$ is omitted in $K_{j l}(j=1,2, \ldots, 5)$. Eccentric phenomena are neglected in equation (3); and $m_{i}=m$ and $J_{c i}=J_{i}=J$ for all investigated lumps. On the basis of these assumptions, vertical governing equations are decoupled from the governing equations of transverse and rotational deformations. Thus, we only study the coupling equations of transverse and rotational deformations to provide the stability condition for the algorithm presented in this study.

On the basis of the above assumption, the corresponding relations between the coefficients used in Timoshenko beam theory and those used in the proposed algorithm are as follows (see Appendix A):

$$
\begin{aligned}
\rho_{0} A_{0} & \Longleftrightarrow \frac{m}{h}, \\
\mathrm{GA}_{s} & \Longleftrightarrow K \cdot h, \\
\rho_{0} I & \Longleftrightarrow \frac{J}{h}, \\
\mathrm{EI} & \Longleftrightarrow(\mathrm{EI}) .
\end{aligned}
$$

3.2. Stability Condition Based on Timoshenko Beam Model. The flexural wave equation of Timoshenko beam is

$$
\frac{\partial^{2} u}{\partial^{2} t}+C_{0}^{2} R^{2} \frac{\partial^{4} u}{\partial^{4} z}-R^{2}\left(1+\frac{C_{0}^{2}}{C_{Q}^{2}}\right) \frac{\partial^{4} u}{\partial^{2} z \partial^{2} t}+\frac{R^{2}}{C_{Q}^{2}} \frac{\partial^{4} u}{\partial^{4} t}=0
$$

where $C_{0}^{2}=\left(E / \rho_{0}\right), R^{2}=\left(I / A_{0}\right)$, and $C_{Q}^{2}=\left(\mathrm{GA}_{s} / \rho_{0} A_{0}\right)$.

Substituting a flexural wave $u=u_{0} e^{i(\omega t-k z)}$ into the finite difference formula of Equation (15), we obtain the following equation (see equation (A.12) in Appendix A):

$$
\begin{gathered}
\frac{4 C_{0}^{2} R^{2}}{h^{4}} \sin ^{4} \frac{k h}{2}-R^{2}\left(1+\frac{C_{0}^{2}}{C_{Q}^{2}}\right) \cdot \frac{4}{h^{2} \Delta t^{2}} \sin ^{2} \frac{\omega \Delta t}{2} \sin ^{2} \frac{k h}{2} \\
+\frac{R^{2}}{C_{Q}^{2}} \frac{4}{\Delta t^{4}} \sin ^{4} \frac{\omega \Delta t}{2}-\frac{1}{\Delta t^{2}} \sin ^{2} \frac{\omega \Delta t}{2}=0 .
\end{gathered}
$$

Solving equation (16) with $\sin ^{2}(\omega \Delta t / 2)$ as unknown yields the following: 


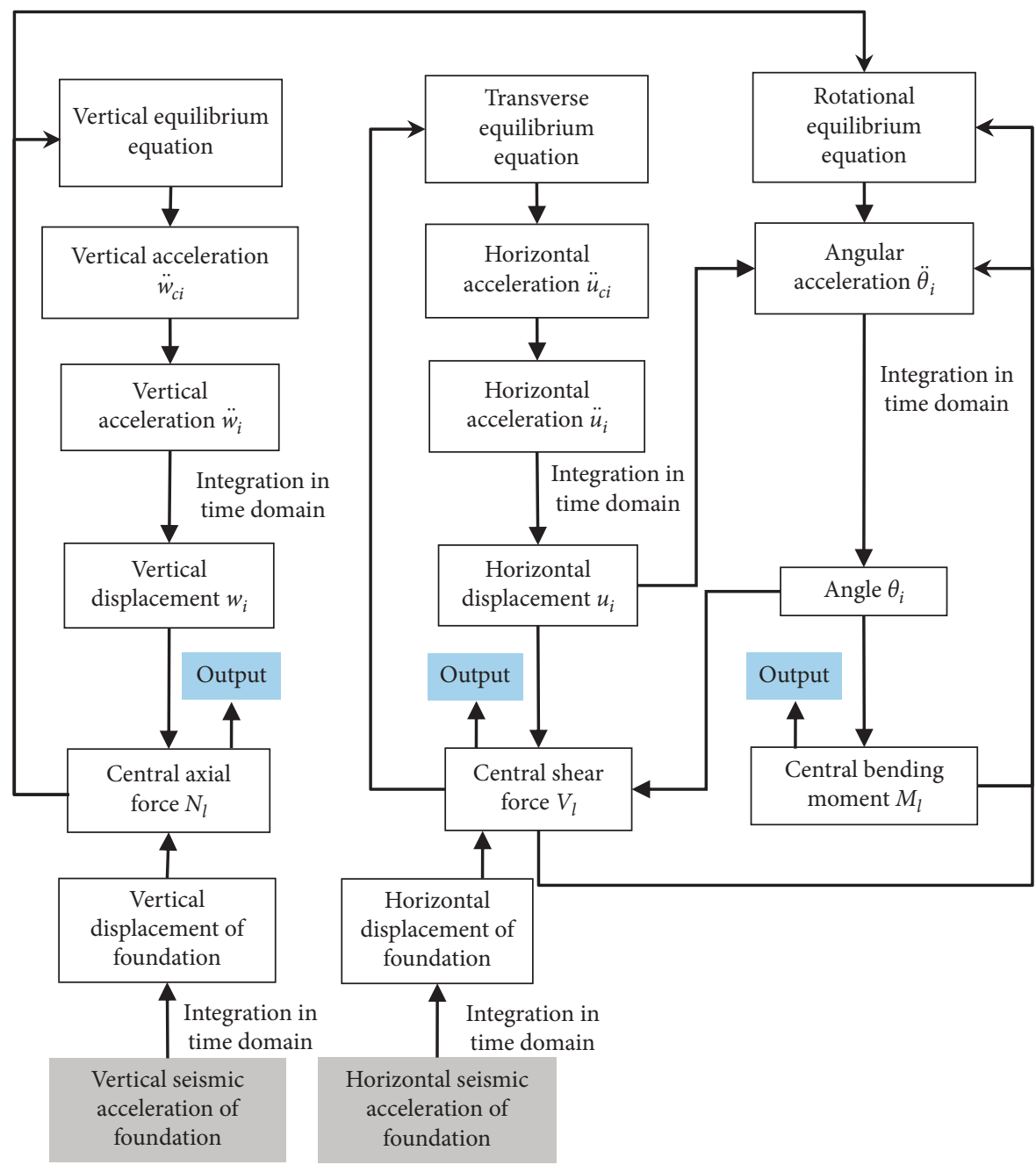

Figure 4: Algorithm description diagram.

$\sin ^{2} \frac{\omega \Delta t}{2}=\Delta t^{2} \frac{\left[\left(C_{0}^{2}+C_{Q}^{2}\right)\left(4 / h^{2}\right) \sin ^{2}(k h / 2)+\left(C_{Q}^{2} / R^{2}\right)\right] \pm \sqrt{\left[\left(C_{0}^{2}+C_{Q}^{2}\right)\left(4 / h^{2}\right) \sin ^{2}(k h / 2)+\left(C_{Q}^{2} / R^{2}\right)\right]^{2}-\left(\left(8 C_{0} C_{Q} / h^{2}\right) \sin ^{2}(k h / 2)\right)^{2}}}{8}$.

Given $\sin ^{2}(\omega \Delta t / 2) \leq 1$, we approximately have the following equation (see equation (A.16) in Appendix A):

$$
\begin{aligned}
\Delta t & \leq \frac{h}{\sqrt{\left(C_{0}^{2}+C_{Q}^{2}\right) \sin ^{2}(k h / 2)+\left(C_{Q}^{2} h^{2} / 4 R^{2}\right)}} \\
& \leq \frac{h}{\sqrt{\left(C_{0}^{2}+C_{Q}^{2}\right)+\left(C_{Q}^{2} h^{2} / 4 R^{2}\right)}} .
\end{aligned}
$$

3.3. Stability Condition for the Proposed Algorithm. The stability condition used in the algorithm presented in this paper can be provided by using equation (18) and the corresponding relations (14) as follows:

$$
\Delta t \leq \frac{h}{\sqrt{((\mathrm{EI}) h / J)+(12(\mathrm{EI}) / m h(1+2 \alpha))+(3(\mathrm{EI}) h / J(1+2 \alpha))}} .
$$

\section{Method Validation}

We study bending wave propagation of a beam to verify the effectiveness of the new algorithm. The beam with equal cross-sectional area is designed to avoid eccentricity. The result given by the finite difference method [29] is used to test the proposed numerical algorithm.

The elastic modulus of the beam is $E=209 \mathrm{GPa}$, density is $\rho=8000 \mathrm{~kg} / \mathrm{m}^{3}$, Poisson's ratio is $v=0.3$, and shear crosssectional correction factor is $k^{\prime}=0.886$. The length of the beam is $X=6.35 \mathrm{~m}$, and the radius is $0.127 \mathrm{~m}$. The number of discrete segments is 500 in the length direction for the 
uniform beam. On the basis of the calculation parameters of the beam, the time step of the beam satisfying the stability condition of the method is $\Delta t \leq 1.51 \mu$ s obtained by equation (19), and the calculation time step is $\Delta t=1.25 \mu \mathrm{s}$.

The length from the left end of the beam is $x$, and the bending moment at the section is $M$. After normalization, the time $\bar{t}$ is $(1 / X) \sqrt{(E / \rho)} t$, the length is $\bar{x}=(x / X)$, and the bending moment is $\bar{M}=(M X / \mathrm{EI})$.

The inclination moment of the left end of the beam is

$$
\bar{M}_{1}= \begin{cases}\overline{\bar{t}}, & 0 \leq \bar{t} \leq \bar{t}_{0}, \\ \bar{t}_{0}, & \bar{t}>\bar{t}_{0} .\end{cases}
$$

Figure 5 shows the comparison curves of the bending moments $\bar{M}$ at different cross sections of the beam at $\bar{t}=7.0554$.

The calculation results of the new numerical method are nearly the same as those of the finite difference method. The comparison results show that the presented algorithm is valid for calculating the earthquake responses of tall $\mathrm{RC}$ chimney.

\section{Earthquake Responses of Tall RC Chimneys}

5.1. Earthquake Records Used. Eleven earthquake acceleration records on four types of soil are used as earthquake load to calculate the structural earthquake response. Four types of soil are denoted by rock, soft rock, stiff soil, and soft soil. Soil type is characterized by shear wave velocity. The corresponding earthquake records are selected from the Pacific Earthquake Engineering Research Center website [30]. Table 1 shows the 11 earthquake records.

According to the peak value of design earthquake acceleration of 8 degrees seismic intensity in the literature [31], the peaks of the horizontal earthquake accelerations are adjusted to $0.2 \mathrm{~g}$ in practical calculations. The peaks of the vertical earthquake accelerations are adjusted to $0.13 \mathrm{~g}$. The damping is omitted.

5.2. Two Models of RC Chimneys. Two RC chimneys [32] of $150 \mathrm{~m}$ and $210 \mathrm{~m}$ height are studied. Figure 6 shows the two models of RC chimneys. (1) The concrete strength grade of the $150 \mathrm{~m}$ high $\mathrm{RC}$ chimney is $\mathrm{C} 25$, and the steel strength grade is HRB335. The outer radius of the bottom is $8.46 \mathrm{~m}$, and the wall thickness is $0.4 \mathrm{~m}$. The outer radius of the top is $3.0 \mathrm{~m}$, and the wall thickness is $0.16 \mathrm{~m}$. The gradient $c$ is 0.1 below $25 \mathrm{~m}, 0.03$ ranging from $25 \mathrm{~m}$ to $75 \mathrm{~m}$, and 0.015 ranging from $75 \mathrm{~m}$ to $150 \mathrm{~m}$. Table 2 shows the parameters of the $150 \mathrm{~m}$ high RC chimney. (2) The concrete strength grade of the $210 \mathrm{~m}$ high RC chimney is C35, and the steel strength grade is HRB335. The outer radius of the bottom is $10.6 \mathrm{~m}$, and the wall thickness is $0.6 \mathrm{~m}$. The outer radius of the top is $3.85 \mathrm{~m}$, and the wall thickness is $0.18 \mathrm{~m}$. The gradient $c$ is 0.1 below $30 \mathrm{~m}, 0.03$ ranging from $30 \mathrm{~m}$ to $100 \mathrm{~m}$, and 0.015 ranging from $100 \mathrm{~m}$ to $210 \mathrm{~m}$. Table 3 shows the parameters of the $210 \mathrm{~m}$ high RC chimney. According to the literature [33], the standard value of the compressive strength of C25

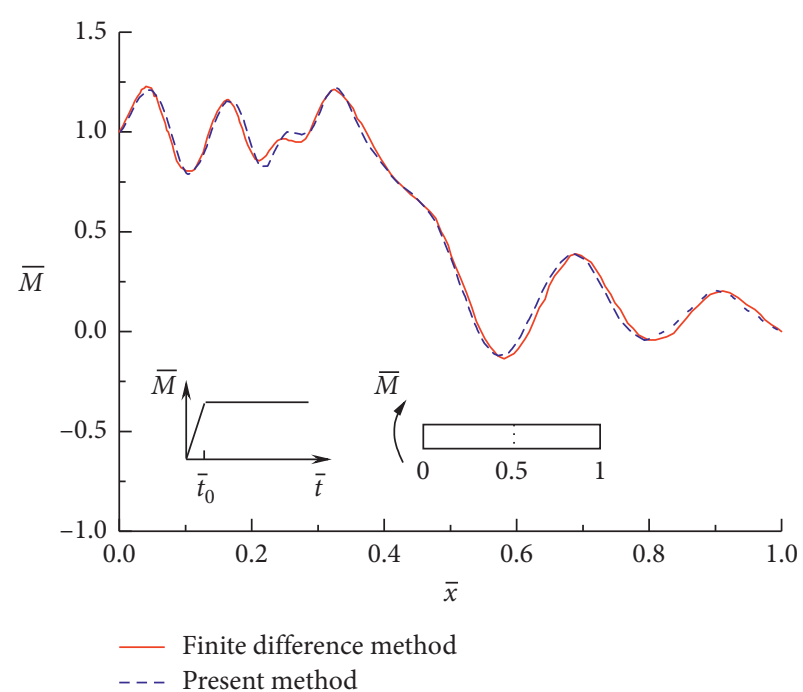

FIGURE 5: Moment distribution along the length of the uniform beam at $\bar{t}=7.0554$.

concrete is $16.7 \mathrm{~N} / \mathrm{mm}^{2}$, the design value is $11.9 \mathrm{~N} / \mathrm{mm}^{2}$, and the elastic modulus is $E_{C}=2.8 \times 10^{4} \mathrm{~N} / \mathrm{mm}^{2}$. The standard value of the compressive strength of C35 concrete is $23.4 \mathrm{~N} /$ $\mathrm{mm}^{2}$, the design value is $16.7 \mathrm{~N} / \mathrm{mm}^{2}$, and the elastic modulus is $E_{C}=3.15 \times 10^{4} \mathrm{~N} / \mathrm{mm}^{2}$. The elastic modulus of HRB335 reinforcement is $E_{S}=2.0 \times 10^{5} \mathrm{~N} / \mathrm{mm}^{2}$, the standard value of strength (yield strength) is $335 \mathrm{~N} / \mathrm{mm}^{2}$, and the design value of strength is $300 \mathrm{~N} / \mathrm{mm}^{2}$.

The discrete segments are all $10 \mathrm{~m}$ long in the vertical direction for each of the two chimneys. Each chimney will become part of such calculated model consisting of several cylinders of different cross-sectional areas because an actual chimney structure has variable cross-sectional areas. Thus, the phenomena of eccentricities between the nodes and the corresponding centroids of the investigated lumps appear in the calculation of the earthquake response of the actual chimney. The mass of each investigated lump consists of half the upper segment and half the lower segment around the discrete node. The moment of inertia of each investigated lump about the horizontal axis through its centroid is calculated. On the basis of the calculation parameters of the $150 \mathrm{~m}$ and $210 \mathrm{~m}$ high chimneys, the time step satisfying the stability condition of the method is obtained by equation (19), $\Delta t \leq 3.4 \mathrm{~ms}$ and $\Delta t \leq 3.1 \mathrm{~ms}$ in the $150 \mathrm{~m}$ and $210 \mathrm{~m}$ high chimneys, respectively. The time step is $1.0 \mathrm{~ms}$.

5.2.1. Effect of Eccentricity. Eleven earthquake waves are used. The effect of eccentricity on normal earthquake stress of the chimney are studied when horizontal and vertical components are inputted simultaneously.

Figure 7 shows the spatial distribution curves of the maximum earthquake normal stresses of different cross sections for the $150 \mathrm{~m}$ high chimney under the actions of Landers (No. 1 in Table 1), Loma Prieta (No. 2), Borrego (No. 3), and Chichi (No. 4) waves. Figure 8 shows the comparison curves of the $210 \mathrm{~m}$ high chimney. "New" 
TABLE 1: Earthquake records used.

\begin{tabular}{|c|c|c|c|c|c|c|}
\hline Serial number & Soil types & Earthquake & Date & Direction & Station and component & PGA (g) \\
\hline \multirow{2}{*}{ No. 1} & \multirow{2}{*}{ Rock } & \multirow{2}{*}{ Landers } & \multirow{2}{*}{$1992 / 06 / 28$} & Horizontal & LANDERS/ABY000 & 0.115 \\
\hline & & & & Vertical & LANDERS/ABY-UP & 0.090 \\
\hline \multirow{2}{*}{ No. 2} & \multirow{2}{*}{ Soft rock } & \multirow{2}{*}{ Loma Prieta } & \multirow{2}{*}{$1989 / 10 / 18$} & Horizontal & LOMAP/CLS000 & 0.644 \\
\hline & & & & Vertical & LOMAP/CLS-UP & 0.455 \\
\hline \multirow{2}{*}{ No. 3} & \multirow{2}{*}{ Stiff soil } & \multirow{2}{*}{ Borrego } & \multirow{2}{*}{$1942 / 10 / 21$} & Horizontal & BORREGO/B-ELC000 & 0.033 \\
\hline & & & & Vertical & BORREGO/B-ELC-UP & 0.068 \\
\hline \multirow{2}{*}{ No. 4} & \multirow{2}{*}{ Soft soil } & \multirow{2}{*}{ Chichi } & \multirow{2}{*}{$1999 / 09 / 20$} & Horizontal & CHICHI/CHY004-N & 0.100 \\
\hline & & & & Vertical & CHICHI/CHY004-V & 0.041 \\
\hline \multirow{2}{*}{ No. 5} & \multirow{2}{*}{ Rock } & \multirow{2}{*}{ Morgan Hill } & \multirow{2}{*}{$1984 / 04 / 24$} & Horizontal & MORGAN/G01230 & 0.069 \\
\hline & & & & Vertical & MORGAN/G01-UP & 0.092 \\
\hline \multirow{2}{*}{ No. 6} & \multirow{2}{*}{ Soft rock } & \multirow{2}{*}{ Loma Prieta } & \multirow{2}{*}{$1989 / 10 / 18$} & Horizontal & LOMAP/GGB360 & 0.123 \\
\hline & & & & Vertical & LOMAP/GGB-UP & 0.056 \\
\hline \multirow{2}{*}{ No. 7} & \multirow{2}{*}{ Stiff soil } & \multirow{2}{*}{ Chichi } & \multirow{2}{*}{$1999 / 09 / 20$} & Horizontal & CHICHI CHY028-N & 0.821 \\
\hline & & & & Vertical & CHICHI CHY028-V & 0.337 \\
\hline \multirow{2}{*}{ No. 8} & \multirow{2}{*}{ Stiff soil } & \multirow{2}{*}{ Chichi } & \multirow{2}{*}{$1999 / 09 / 20$} & Horizontal & CHICHI TCU076-N & 0.416 \\
\hline & & & & Vertical & CHICHI TCU076-V & 0.281 \\
\hline \multirow{2}{*}{ No. 9} & \multirow{2}{*}{ Stiff soil } & Moroan Hill & $1984 / 04 / 24$ & Horizontal & MORGAN/G03090 & 0.200 \\
\hline & & Morgan Hill & $1984 / 04 / 24$ & Vertical & MORGAN/G03-UP & 0.395 \\
\hline & & & & Horizontal & MORGAN HVR240 & 0.312 \\
\hline No. 10 & Stift soil & Morgan Hill & $1984 / 04 / 24$ & Vertical & MORGAN HVR-UP & 0.110 \\
\hline No. 11 & Soft soil & Impe & $1079 / 10 / 15$ & Horizontal & IMPVALL H-E03140 & 0.266 \\
\hline No. 11 & soll soll & Imperial valley & $10 / 9 / 10 / 15$ & Vertical & IMPVALL H-E03-UP & 0.127 \\
\hline
\end{tabular}

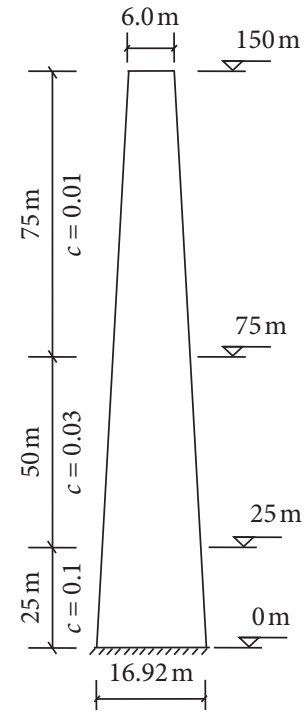

(a)

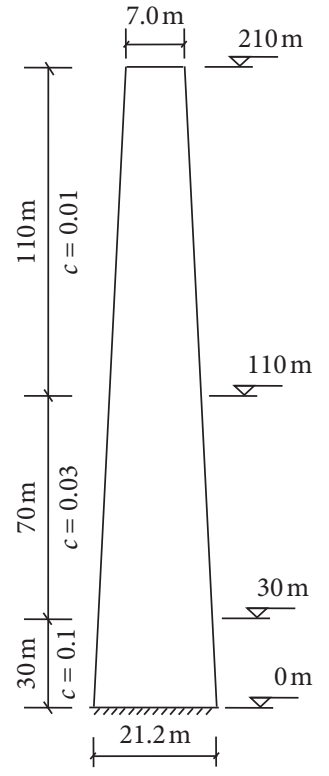

(b)

Figure 6: Model of (a) $150 \mathrm{~m}$ and (b) $210 \mathrm{~m}$ high chimneys.

denotes that the phenomena of eccentricities are considered. "Conventional" denotes the conventional results, in which the phenomena of eccentricities are neglected, for the earthquake responses of the real RC chimneys. Dashed lines ("tensile") denote tensile stresses, whereas solid lines ("press") denote compressive stresses.

A comparison of the red solid lines and the blue solid lines in Figures 7 and 8 shows that the increased phenomena of peak values of the normal compressive stresses appear when eccentricities are considered.
A comparison of the red dashed lines and the blue dashed lines in Figures 7 and 8 shows that the increased phenomena of peak values of the normal tensile stresses appear when eccentricities are considered.

Table 4 shows the details of the increase in percentage of maximum earthquake normal tensile/compressive stresses when phenomena of eccentricities are considered.

Table 5 shows maximum earthquake compressive stress, mean value, and standard deviation of different sections of the $150 \mathrm{~m}$ high chimney under 11 earthquake 
TABle 2: Parameters of $150 \mathrm{~m}$ high RC chimney.

\begin{tabular}{lccc}
\hline Elevation $(\mathrm{m})$ & Outer radius $(\mathrm{m})$ & Wall thickness $(\mathrm{m})$ & Reinforcement ratio $(\%)$ \\
\hline 150 & 3.00 & 0.16 & 0.45 \\
137.5 & 3.52 & 0.16 & 0.47 \\
125 & 3.71 & 0.16 & 0.47 \\
112.5 & 3.89 & 0.18 & 0.42 \\
100 & 4.08 & 0.18 & 0.42 \\
87.5 & 4.27 & 0.22 & 0.47 \\
75 & 4.46 & 0.22 & 0.47 \\
62.5 & 4.83 & 0.26 & 0.52 \\
50 & 5.21 & 0.26 & 0.52 \\
37.5 & 5.58 & 0.34 & 0.50 \\
25 & 5.96 & 0.34 & 0.50 \\
5 & 7.96 & 0.40 & 0.52 \\
0 & 8.46 & 0.40 & 0.52 \\
\hline
\end{tabular}

TABle 3: Parameters of $210 \mathrm{~m}$ high RC chimney.

\begin{tabular}{lccc}
\hline Elevation $(\mathrm{m})$ & Outer radius $(\mathrm{m})$ & Wall thickness $(\mathrm{m})$ & Reinforcement ratio $(\%)$ \\
\hline 210 & 3.50 & 0.18 & 0.57 \\
190 & 4.15 & 0.18 & 0.57 \\
170 & 4.45 & 0.20 & 0.51 \\
150 & 4.75 & 0.20 & 0.67 \\
130 & 5.05 & 0.20 & 0.67 \\
120 & 5.20 & 0.23 & 0.74 \\
110 & 5.35 & 0.26 & 0.65 \\
100 & 5.50 & 0.29 & 0.58 \\
90 & 5.80 & 0.32 & 0.65 \\
80 & 6.10 & 0.35 & 0.60 \\
70 & 6.40 & 0.38 & 0.67 \\
60 & 6.70 & 0.41 & 0.62 \\
50 & 7.00 & 0.44 & 0.74 \\
40 & 7.30 & 0.47 & 0.70 \\
30 & 7.60 & 0.50 & 0.65 \\
0.5 & 8.95 & 0.53 & 0.77 \\
\hline
\end{tabular}

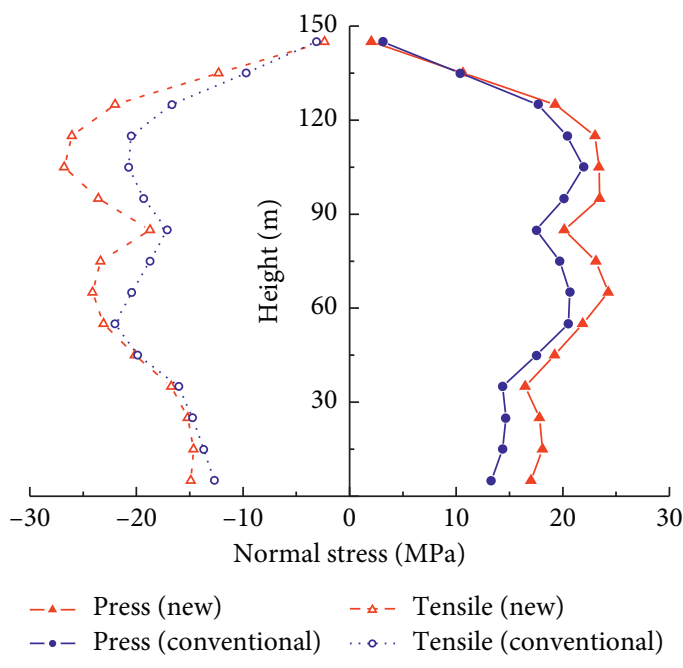

(a)

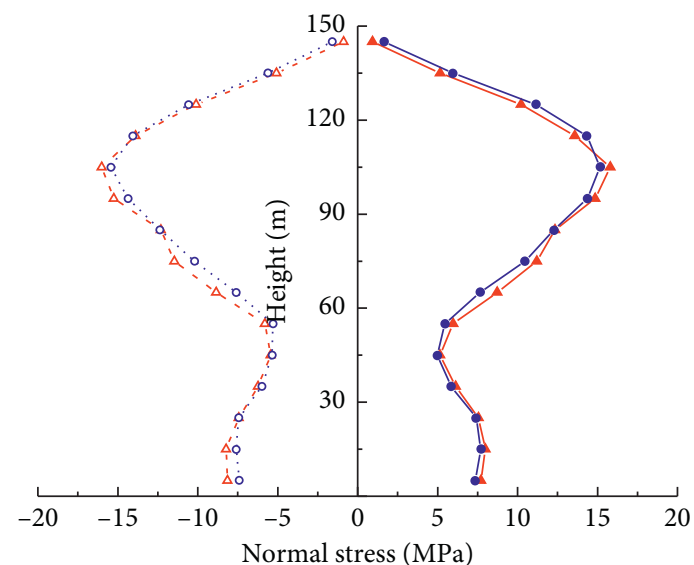

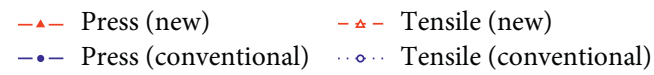

(b)

Figure 7: Continued. 


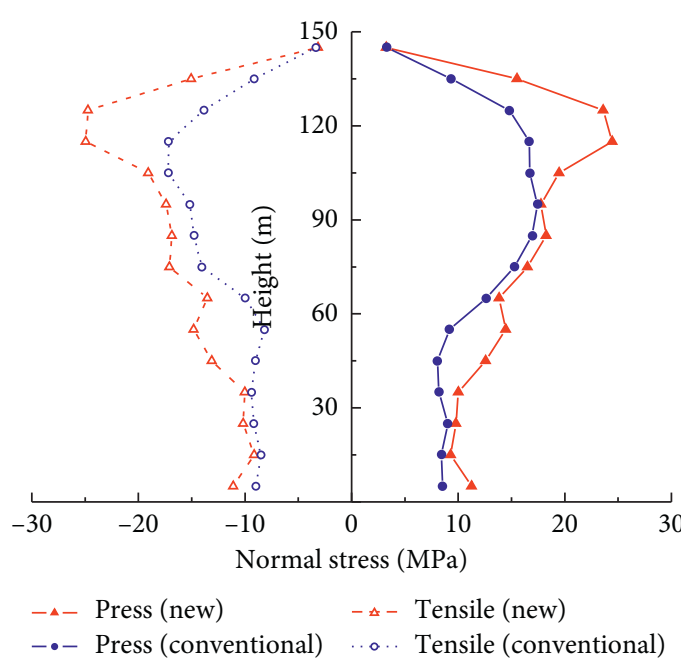

(c)

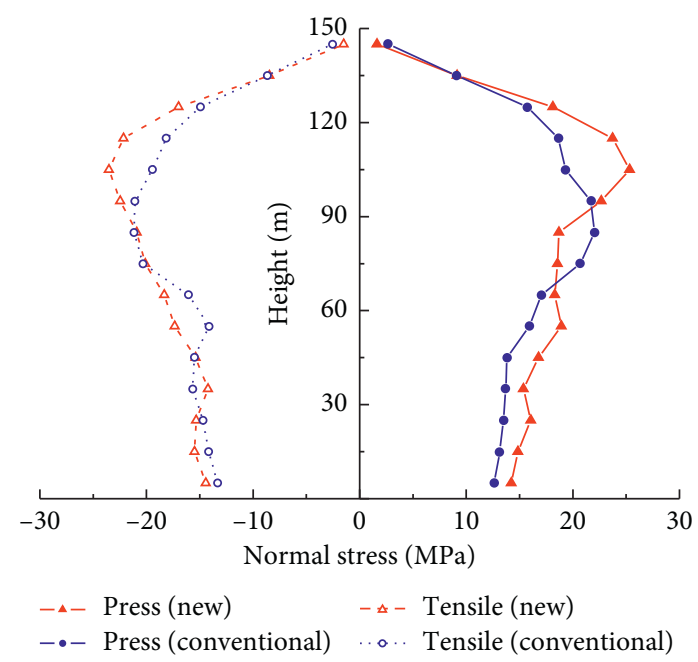

(d)

FIGURE 7: Spatial distributions of maximum earthquake normal stresses at different cross sections of the $150 \mathrm{~m}$ high chimney under four earthquake wave actions: (a) Landers wave (No. 1 in Table 1); (b) Loma Prieta wave (No. 2); (c) Borrego wave (No. 3); (d) Chichi wave (No. 4).

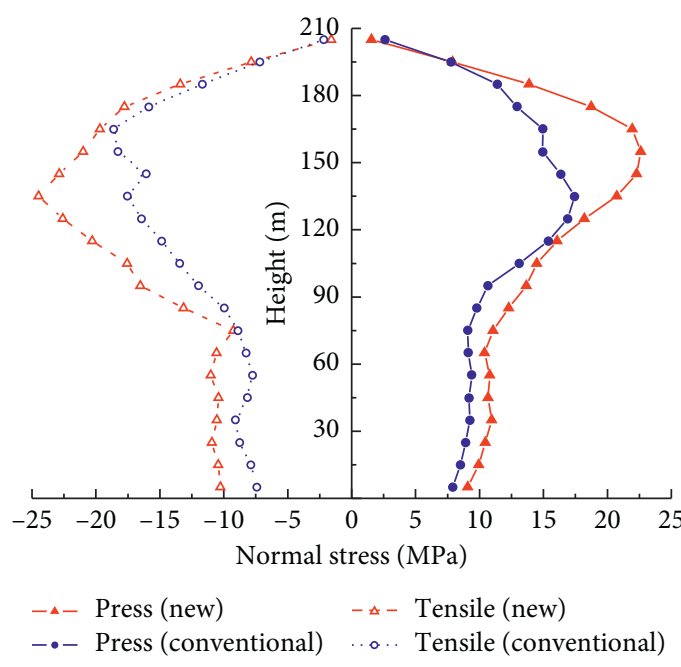

(a)

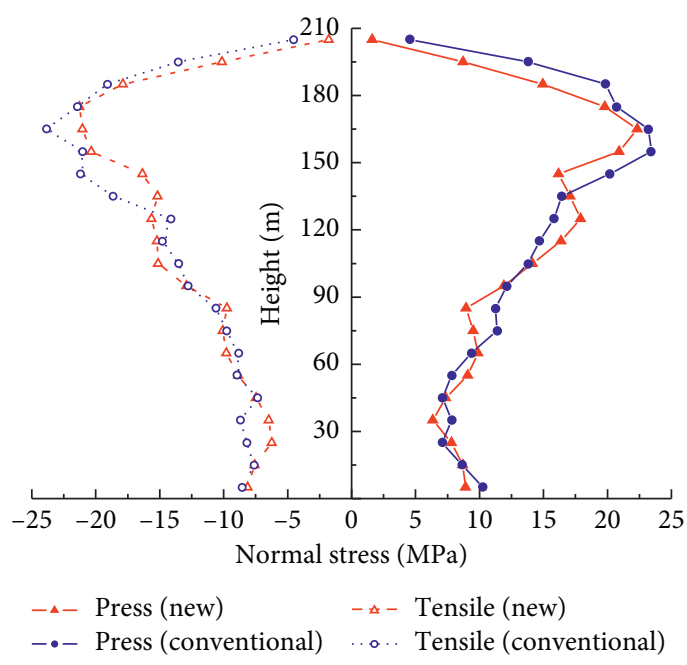

(c)

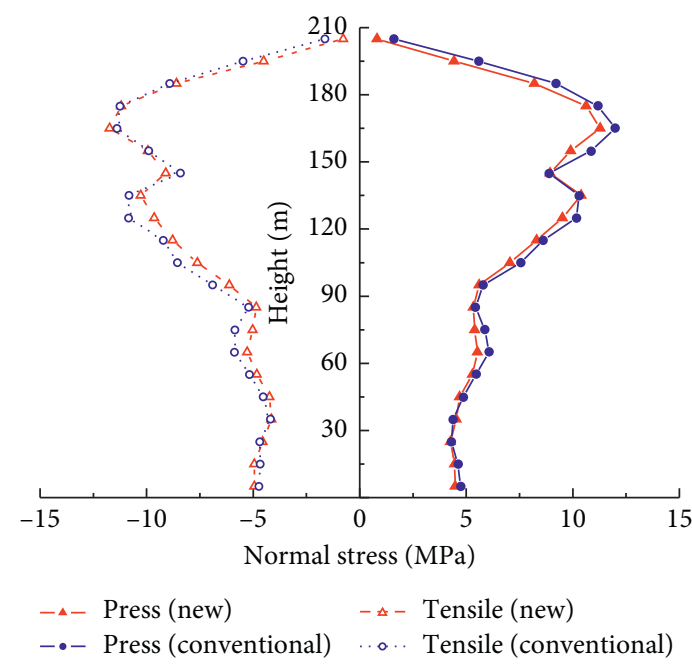

(b)

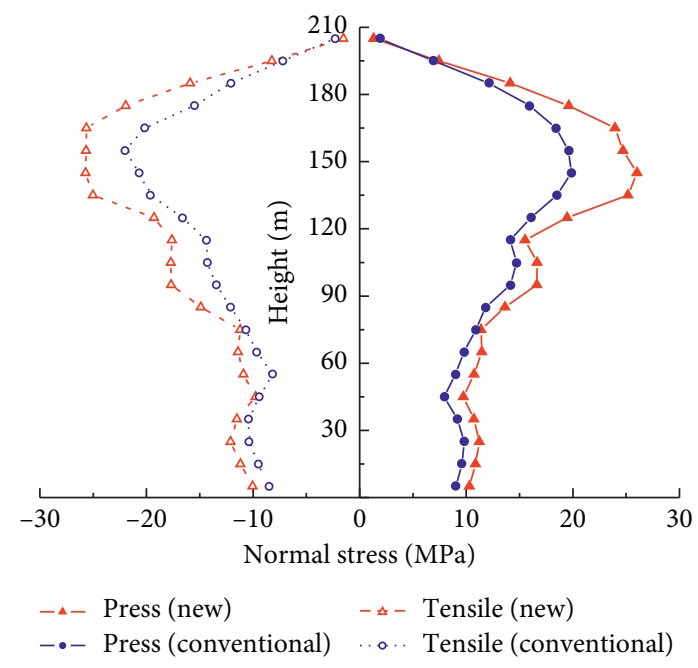

(d)

FIGURE 8: Spatial distributions of maximum earthquake normal stresses at different cross sections of the $210 \mathrm{~m}$ high chimney under four earthquake wave actions: (a) Landers wave (No. 1); (b) Loma Prieta wave (No. 2); (c) Borrego wave (No. 3); (d) Chichi wave (No. 4). 
TABLe 4: Percentages of increase in maximum earthquake normal stresses.

\begin{tabular}{lcccc}
\hline \multirow{2}{*}{ Seismic waves } & & Maximum earthquake normal stresses increased & & \\
& & & & \\
& & & \\
& & & \\
Landers (No. 1) & $7 \%$ (compressive) & $29 \%$ (tensile) & $30 \%$ (compressive) & $31 \%$ (tensile) \\
Loma Prieta (No. 2) & $4 \%$ (compressive) & $4 \%$ (tensile) & $-6 \%$ (compressive) & $3 \%($ tensile) \\
Borrego (No. 3) & $40 \%$ (compressive) & $45 \%$ (tensile) & $-5 \%$ (compressive) & $-11 \%($ tensile) \\
Chichi (No. 4) & $15 \%$ (compressive) & $11 \%$ (tensile) & $31 \%$ (compressive) & $17 \%$ (tensile) \\
\hline
\end{tabular}

TABle 5: Maximum earthquake compressive stresses of the $150 \mathrm{~m}$ high chimney under the action of 11 earthquake waves considering vertical eccentricities.

\begin{tabular}{|c|c|c|c|c|c|c|c|c|c|c|c|c|c|}
\hline \multirow{2}{*}{ High } & \multicolumn{13}{|c|}{ Serial number } \\
\hline & 1 & 2 & 3 & 4 & 5 & 6 & 7 & 8 & 9 & 10 & 11 & Mean & Standard deviation \\
\hline 5 & 17.010 & 7.717 & 11.246 & 14.230 & 3.482 & 10.097 & 5.921 & 7.997 & 3.671 & 6.339 & 7.160 & 8.625 & 4.215 \\
\hline 15 & 18.103 & 7.988 & 9.306 & 14.845 & 2.561 & 10.899 & 6.311 & 8.594 & 3.176 & 6.847 & 7.752 & 8.762 & 4.583 \\
\hline 25 & 17.811 & 7.554 & 9.795 & 16.047 & 2.853 & 11.025 & 6.220 & 7.992 & 3.318 & 6.901 & 9.003 & 8.956 & 4.662 \\
\hline 35 & 16.475 & 6.128 & 10.006 & 15.363 & 3.864 & 9.321 & 5.186 & 7.083 & 4.455 & 6.180 & 8.760 & 8.438 & 4.190 \\
\hline 45 & 19.225 & 5.138 & 12.582 & 16.774 & 5.095 & 6.611 & 4.861 & 6.217 & 4.728 & 4.847 & 8.994 & 8.643 & 5.222 \\
\hline 55 & 21.856 & 5.972 & 14.454 & 18.917 & 4.458 & 7.092 & 5.830 & 6.942 & 4.052 & 4.971 & 8.281 & 9.348 & 6.172 \\
\hline 65 & 24.280 & 8.720 & 13.826 & 18.302 & 4.572 & 12.040 & 7.450 & 9.123 & 4.556 & 6.848 & 9.922 & 10.876 & 6.010 \\
\hline 75 & 23.119 & 11.202 & 16.489 & 18.571 & 5.310 & 16.889 & 8.408 & 11.441 & 5.503 & 10.154 & 11.935 & 12.638 & 5.573 \\
\hline 85 & 20.135 & 12.336 & 18.254 & 18.691 & 4.395 & 19.644 & 8.477 & 12.966 & 5.251 & 11.897 & 12.518 & 13.142 & 5.579 \\
\hline 95 & 23.456 & 14.853 & 17.752 & 22.674 & 5.197 & 21.044 & 9.936 & 15.339 & 6.017 & 13.187 & 12.684 & 14.740 & 6.205 \\
\hline 105 & 23.388 & 15.798 & 19.462 & 25.328 & 5.928 & 20.219 & 10.333 & 17.028 & 6.852 & 13.349 & 11.428 & 15.374 & 6.429 \\
\hline 115 & 23.024 & 13.572 & 24.448 & 23.733 & 7.695 & 16.853 & 9.306 & 14.868 & 7.790 & 12.157 & 10.025 & 14.861 & 6.370 \\
\hline 125 & 19.287 & 10.223 & 23.603 & 18.134 & 8.715 & 11.734 & 7.027 & 11.008 & 7.465 & 9.020 & 8.885 & 12.282 & 5.508 \\
\hline 135 & 10.645 & 5.170 & 15.509 & 9.135 & 6.332 & 5.451 & 3.760 & 6.105 & 4.277 & 4.523 & 5.318 & 6.929 & 3.522 \\
\hline 145 & 2.028 & 0.928 & 3.245 & 1.614 & 1.427 & 0.880 & 0.714 & 1.370 & 0.909 & 0.823 & 1.085 & 1.366 & 0.740 \\
\hline
\end{tabular}

TABle 6: Maximum earthquake compressive stresses of the $150 \mathrm{~m}$ chimney under the action of 11 earthquake waves ignoring vertical eccentricities.

\begin{tabular}{|c|c|c|c|c|c|c|c|c|c|c|c|c|c|}
\hline \multirow{2}{*}{ High } & \multicolumn{13}{|c|}{ Serial number } \\
\hline & 1 & 2 & 3 & 4 & 5 & 6 & 7 & 8 & 9 & 10 & 11 & Mean & Standard deviation \\
\hline 5 & 13.289 & 7.369 & 8.554 & 12.633 & 3.384 & 10.305 & 5.134 & 7.313 & 3.331 & 5.934 & 6.745 & 7.636 & 3.341 \\
\hline 15 & 14.345 & 7.691 & 8.419 & 13.151 & 2.551 & 11.081 & 5.622 & 7.949 & 2.885 & 5.974 & 7.481 & 7.923 & 3.773 \\
\hline 25 & 14.663 & 7.413 & 9.033 & 13.475 & 2.504 & 11.043 & 5.951 & 7.640 & 3.002 & 5.274 & 8.561 & 8.051 & 3.902 \\
\hline 35 & 14.349 & 5.850 & 8.187 & 13.705 & 2.992 & 9.354 & 6.185 & 6.321 & 3.458 & 5.063 & 8.813 & 7.661 & 3.731 \\
\hline 45 & 17.519 & 4.976 & 8.059 & 13.816 & 4.116 & 7.107 & 6.016 & 6.577 & 3.657 & 4.618 & 8.719 & 7.744 & 4.307 \\
\hline 55 & 20.530 & 5.451 & 9.178 & 15.920 & 4.751 & 7.269 & 6.060 & 7.221 & 3.133 & 4.536 & 8.345 & 8.400 & 5.264 \\
\hline 65 & 20.660 & 7.658 & 12.663 & 17.034 & 3.858 & 11.333 & 7.614 & 8.218 & 3.604 & 6.526 & 9.731 & 9.900 & 5.263 \\
\hline 75 & 19.725 & 10.469 & 15.268 & 20.713 & 4.605 & 15.857 & 8.474 & 9.739 & 5.055 & 8.741 & 11.681 & 11.848 & 5.426 \\
\hline 85 & 17.501 & 12.267 & 16.931 & 22.010 & 4.934 & 18.636 & 8.167 & 10.660 & 5.284 & 10.439 & 12.392 & 12.656 & 5.552 \\
\hline 95 & 20.104 & 14.349 & 17.435 & 21.680 & 5.011 & 20.800 & 8.797 & 12.931 & 5.334 & 11.404 & 12.197 & 13.640 & 5.891 \\
\hline 105 & 21.951 & 15.170 & 16.700 & 19.318 & 5.453 & 20.830 & 9.370 & 15.129 & 5.800 & 10.514 & 11.032 & 13.752 & 5.745 \\
\hline 115 & 20.385 & 14.337 & 16.688 & 18.629 & 7.109 & 18.066 & 8.969 & 14.270 & 6.014 & 8.398 & 9.452 & 12.938 & 5.122 \\
\hline 125 & 17.655 & 11.136 & 14.798 & 15.712 & 7.554 & 13.324 & 7.386 & 10.924 & 5.278 & 6.956 & 8.047 & 10.797 & 4.106 \\
\hline 135 & 10.348 & 5.974 & 9.327 & 9.096 & 5.879 & 6.914 & 4.598 & 6.387 & 3.223 & 4.267 & 4.705 & 6.429 & 2.300 \\
\hline 145 & 3.091 & 1.632 & 3.315 & 2.693 & 2.384 & 1.875 & 1.460 & 2.273 & 1.196 & 1.333 & 1.554 & 2.073 & 0.728 \\
\hline
\end{tabular}

wave actions when vertical eccentricities are considered. Table 6 shows maximum earthquake compressive stress, mean value, and standard deviation when vertical eccentricities are ignored.

In Table 5, the comparison of the data shows that the maximum earthquake compressive stress obtained under different earthquake waves is significantly different, and the degree of the difference can be expressed by the standard deviation. To quantify the degree of difference, its standard deviation $S$ is

$$
S=\sqrt{\frac{\sum_{l=1}^{n}\left(\sigma_{l}-\bar{\sigma}\right)^{2}}{n-1}},
$$

where $n$ is the number of samples, that is, the number of selected earthquake waves; $\sigma_{l}$ is normal stress on the central section of segment $l$, that is, the sum of bending stress and axial stress, which is $\sigma_{l}=\left(M_{l} / W_{l}\right)+$ $\left(N_{l} / A_{l}\right) ; W_{l}$ is the bending-resistance modulus of the segment $l$; and $\bar{\sigma}$ is the mean normal stress of the central section. 


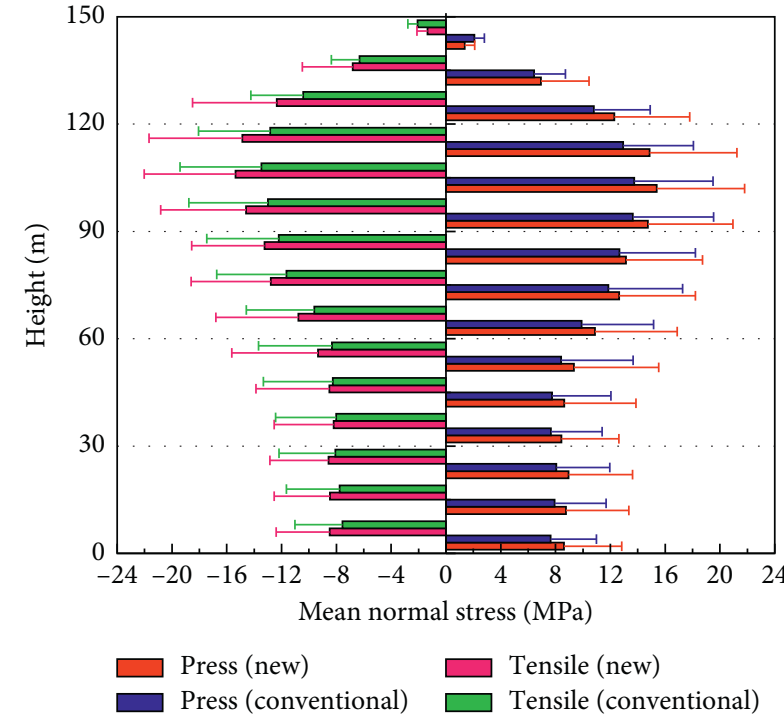

(a)

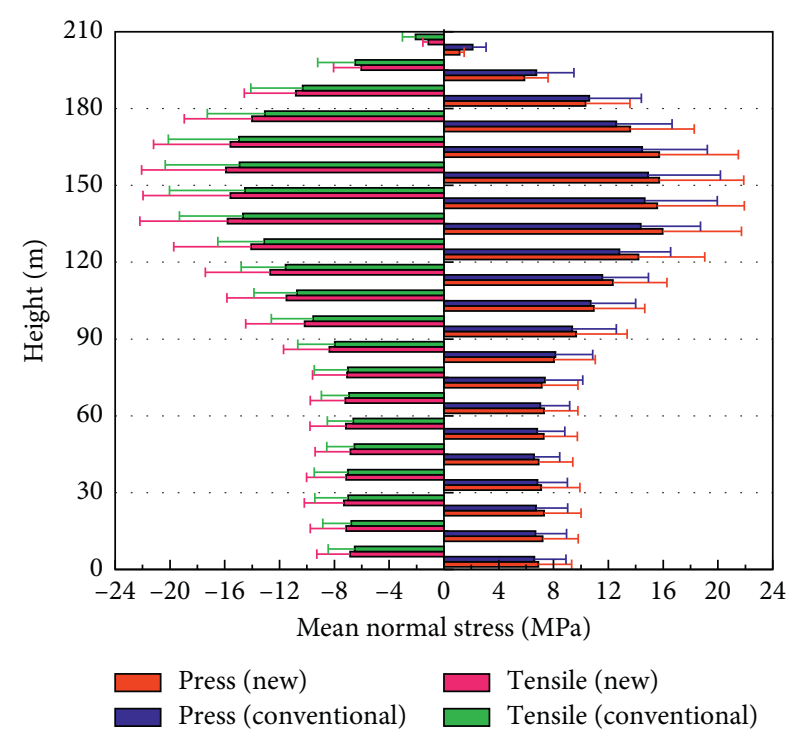

(b)

FIGURE 9: Comparisons of mean and standard deviation of the normal stress of chimney: (a) $150 \mathrm{~m}$ high chimney; (b) $210 \mathrm{~m}$ high chimney.

TABLE 7: Maximum earthquake tensile stresses of the $150 \mathrm{~m}$ high chimney considering vertical eccentricities.

\begin{tabular}{|c|c|c|c|c|c|c|c|c|c|c|c|c|c|}
\hline \multirow[b]{2}{*}{ High } & \multicolumn{13}{|c|}{ Serial number } \\
\hline & 1 & 2 & 3 & 4 & 5 & 6 & 7 & 8 & 9 & 10 & 11 & Mean & $\begin{array}{l}\text { Standard } \\
\text { deviation }\end{array}$ \\
\hline 5 & -14.899 & -8.142 & -11.107 & -14.432 & -3.545 & -10.385 & $-5.5>$ & -1 & -3.008 & -7. & -1 & 4 & 3.918 \\
\hline 15 & -14.643 & -8.224 & -9.130 & 15.498 & -3.170 & -11.141 & -6.012 & -8.139 & -2.637 & -7.0 & -7.417 & & 79 \\
\hline 25 & -15.184 & -7.429 & -10.161 & 15.337 & -2.699 & -11.614 & -6.114 & -8.303 & -2.496 & -6.597 & -8.329 & -8.569 & 290 \\
\hline 35 & -16.726 & -6.233 & -10.023 & -14.233 & -2.904 & -9.964 & -5.454 & -7.328 & -2.928 & -5.911 & -8.414 & -8.193 & 4.345 \\
\hline 45 & -20.149 & -5.441 & -13.105 & -15.379 & -3.684 & -7.288 & -5.441 & -5.944 & -3.742 & -5.080 & -8.275 & -8.502 & 5.371 \\
\hline 55 & -23.087 & -5.802 & -14.819 & -17.339 & -3.907 & -7.209 & -6.053 & -6.328 & -4.228 & -4.772 & -9.252 & -9 & 296 \\
\hline 65 & -24.106 & -8.842 & -13.522 & -18.325 & -4.194 & -11.620 & -6.900 & -8.679 & -4.588 & -6.925 & -10.773 & -10.770 & 021 \\
\hline 75 & -23.367 & -11.458 & -17.079 & -20.100 & -5.300 & -16.431 & -8.021 & -11.427 & -5.875 & -10.037 & -11.643 & -12.794 & 5.798 \\
\hline 85 & -18.712 & -12.305 & -16.848 & -20.900 & -5.449 & -19.142 & -8.437 & -12.990 & -5.350 & -12.505 & -12.969 & -13.237 & 5.330 \\
\hline 95 & -23.568 & -15.257 & -17.401 & -22.463 & -5.488 & -20.761 & -9.536 & -14.479 & -5.326 & -13.449 & -12.741 & -14.588 & \\
\hline 105 & -26.781 & -16.007 & -19.081 & -23.512 & -6.008 & -19.810 & -10.048 & -15.935 & -6.174 & -12.991 & -12.563 & -15 & 6.669 \\
\hline 115 & -26.059 & -13.898 & -24.943 & -22.161 & -7.670 & -16.399 & -9.067 & -14.409 & -6.982 & -11.603 & -10.365 & -14.869 & 6.797 \\
\hline 125 & -21.997 & -10.105 & -24.736 & -16.982 & -8.222 & -11.353 & -6.804 & -10.998 & -7.044 & -8.738 & -8.935 & -12.356 & 6.136 \\
\hline 135 & -12.284 & -5.071 & -15.064 & -8.473 & -5.732 & -5.321 & -3.660 & -5.796 & -4.293 & -4.246 & -4.992 & -6.812 & 3.667 \\
\hline 145 & -2.349 & -0.883 & -3.139 & -1.509 & -1.387 & -0.863 & -0.744 & -1.380 & -0.862 & -0.817 & -0.948 & -1.353 & 0.757 \\
\hline
\end{tabular}

TABLE 8: Maximum earthquake tensile stresses of the $150 \mathrm{~m}$ high chimney ignoring vertical eccentricities.

\begin{tabular}{lccccccccccccc}
\hline High & 1 & 2 & 3 & 4 & 5 & 6 & 7 & 8 & 9 & 10 & 11 & Mean & Standard deviation \\
\hline 5 & -12.713 & -7.405 & -8.992 & -13.313 & -3.442 & -10.154 & -5.158 & -7.275 & -2.661 & -5.482 & -6.441 & -7.549 & 3.476 \\
15 & -13.689 & -7.593 & -8.485 & -14.183 & -2.785 & -10.792 & -5.623 & -7.339 & -2.313 & -5.516 & -7.092 & -7.765 & 3.883 \\
25 & -14.737 & -7.445 & -9.195 & -14.689 & -2.622 & -11.050 & -5.718 & -7.167 & -2.953 & -5.404 & -7.922 & -8.082 & 4.101 \\
35 & -16.038 & -5.984 & -9.391 & -15.677 & -2.783 & -9.446 & -5.863 & -6.125 & -3.703 & -4.969 & -8.241 & -8.020 & 4.412 \\
45 & -19.887 & -5.361 & -9.031 & -15.521 & -4.038 & -7.266 & -5.923 & -6.521 & -3.986 & -4.520 & -8.731 & -8.253 & 5.066 \\
55 & -22.010 & -5.296 & -8.157 & -14.138 & -4.718 & -7.033 & -6.395 & -7.338 & -3.525 & -4.671 & -8.345 & -8.330 & 5.348 \\
65 & -20.442 & -7.589 & -9.998 & -16.058 & -3.955 & -11.176 & -7.868 & -8.750 & -3.820 & -6.332 & -9.822 & -9.619 & 4.957 \\
75 & -18.744 & -10.206 & -14.035 & -20.320 & -4.984 & -15.659 & -8.765 & -10.409 & -5.016 & -8.449 & -11.561 & -11.650 & 5.078 \\
85 & -17.127 & -12.362 & -14.803 & -21.183 & -4.995 & -18.267 & -8.545 & -10.835 & -4.926 & -9.392 & -11.886 & -12.211 & 5.259 \\
95 & -19.308 & -14.363 & -15.150 & -21.096 & -5.158 & -20.466 & -8.701 & -12.565 & -4.347 & -9.829 & -11.888 & -12.988 & 5.778 \\
105 & -20.735 & -15.441 & -17.201 & -19.442 & -5.141 & -21.169 & -9.351 & -14.565 & -4.676 & -9.461 & -10.996 & -13.471 & 5.938 \\
115 & -20.512 & -14.054 & -17.158 & -18.152 & -6.723 & -18.408 & -9.040 & -13.521 & -5.411 & -8.833 & -9.374 & -12.835 & 5.232 \\
125 & -16.682 & -10.576 & -13.862 & -14.924 & -6.909 & -13.614 & -7.317 & -10.586 & -5.691 & -7.308 & -7.275 & -10.431 \\
135 & -9.702 & -5.606 & -9.130 & -8.663 & -5.585 & -7.096 & -4.223 & -6.238 & -4.007 & -4.296 & -4.774 & -6.302 & 3.814 \\
145 & -3.090 & -1.589 & -3.339 & -2.557 & -2.419 & -1.928 & -1.258 & -2.233 & -1.350 & -1.345 & -1.680 & -2.072 & 0.067 \\
\hline
\end{tabular}


TABLE 9: Maximum earthquake compressive stresses of the $210 \mathrm{~m}$ high chimney considering vertical eccentricities.

\begin{tabular}{|c|c|c|c|c|c|c|c|c|c|c|c|c|c|}
\hline \multirow{2}{*}{ High } & \multicolumn{13}{|c|}{ Serial number } \\
\hline & 1 & 2 & 3 & 4 & 5 & 6 & 7 & 8 & 9 & 10 & 11 & Mean & Standard deviation \\
\hline 5 & 9.073 & 4.481 & 8.898 & 10.293 & 2.941 & 9.218 & 3.664 & 7.445 & 6.273 & 6.974 & 6.646 & 6.901 & 2.416 \\
\hline 15 & 9.938 & 4.449 & 8.687 & 10.863 & 3.229 & 9.964 & 3.797 & 8.021 & 6.456 & 7.002 & 6.773 & 7.198 & 2.591 \\
\hline 25 & 10.466 & 4.260 & 7.814 & 11.223 & 3.642 & 10.552 & 3.865 & 8.428 & 6.349 & 6.810 & 6.874 & 7.298 & 2.707 \\
\hline 35 & 10.942 & 4.536 & 6.342 & 10.703 & 3.143 & 10.389 & 3.755 & 8.574 & 5.477 & 6.347 & 7.981 & 7.108 & 2.806 \\
\hline 45 & 10.664 & 4.682 & 7.363 & 9.732 & 4.033 & 9.170 & 3.919 & 8.081 & 4.383 & 5.379 & 8.613 & 6.911 & 2.501 \\
\hline 55 & 10.790 & 5.288 & 9.082 & 10.740 & 4.553 & 7.951 & 4.411 & 7.829 & 4.681 & 5.806 & 9.083 & 7.292 & 2.452 \\
\hline 65 & 10.391 & 5.523 & 9.869 & 11.456 & 4.298 & 7.003 & 4.417 & 7.768 & 5.244 & 5.932 & 8.403 & 7.300 & 2.480 \\
\hline 75 & 11.058 & 5.397 & 9.500 & 11.388 & 4.244 & 5.592 & 4.090 & 7.069 & 5.027 & 6.239 & 8.873 & 7.134 & 2.653 \\
\hline 85 & 12.283 & 5.330 & 8.956 & 13.619 & 4.035 & 7.998 & 4.624 & 8.426 & 5.976 & 8.010 & 9.112 & 8.034 & 3.010 \\
\hline 95 & 13.669 & 5.604 & 11.904 & 16.621 & 4.800 & 11.195 & 5.281 & 10.340 & 7.300 & 9.797 & 9.709 & 9.656 & 3.704 \\
\hline 105 & 14.484 & 7.044 & 14.138 & 16.663 & 5.771 & 13.921 & 5.765 & 11.962 & 9.226 & 10.333 & 11.088 & 10.945 & 3.708 \\
\hline 115 & 16.080 & 8.297 & 16.374 & 15.511 & 6.376 & 17.064 & 6.771 & 14.798 & 11.033 & 10.732 & 12.649 & 12.335 & 3.950 \\
\hline 125 & 18.201 & 9.514 & 17.908 & 19.468 & 7.501 & 20.617 & 7.767 & 17.874 & 12.290 & 11.079 & 13.899 & 14.192 & 4.836 \\
\hline 135 & 20.731 & 10.387 & 17.076 & 25.177 & 7.543 & 23.166 & 8.884 & 19.191 & 15.434 & 13.947 & 14.108 & 15.968 & 5.754 \\
\hline 145 & 22.279 & 8.930 & 16.182 & 26.017 & 6.539 & 23.188 & 8.091 & 17.090 & 15.283 & 14.884 & 12.716 & 15.564 & 6.365 \\
\hline 155 & 22.605 & 9.904 & 20.913 & 24.714 & 6.672 & 21.495 & 8.269 & 17.399 & 13.326 & 15.063 & 12.582 & 15.722 & 6.154 \\
\hline 165 & 21.942 & 11.283 & 22.329 & 23.957 & 6.477 & 19.121 & 8.648 & 17.038 & 12.612 & 13.700 & 15.753 & 15.715 & 5.766 \\
\hline 175 & 18.729 & 10.621 & 19.787 & 19.615 & 5.954 & 15.222 & 8.110 & 14.354 & 10.513 & 11.494 & 15.196 & 13.600 & 4.668 \\
\hline 185 & 13.872 & 8.191 & 14.943 & 14.117 & 5.435 & 10.425 & 6.618 & 10.449 & 8.133 & 8.744 & 12.918 & 10.349 & 3.233 \\
\hline 195 & 7.892 & 4.429 & 8.716 & 7.440 & 4.429 & 5.082 & 3.846 & 5.557 & 4.556 & 4.826 & 7.781 & 5.868 & 1.735 \\
\hline 205 & 1.547 & 0.811 & 1.607 & 1.321 & 1.283 & 0.827 & 0.769 & 1.046 & 0.833 & 0.868 & 1.611 & 1.138 & 0.343 \\
\hline
\end{tabular}

TABLE 10: Maximum earthquake compressive stresses of the $210 \mathrm{~m}$ high chimney ignoring vertical eccentricities.

\begin{tabular}{|c|c|c|c|c|c|c|c|c|c|c|c|c|c|}
\hline \multirow{2}{*}{ High } & \multicolumn{13}{|c|}{ Serial number } \\
\hline & 1 & 2 & 3 & 4 & 5 & 6 & 7 & 8 & 9 & 10 & 11 & Mean & Standard deviation \\
\hline 5 & 7.913 & 4.726 & 10.278 & 9.045 & 3.297 & 7.885 & 3.325 & 8.324 & 5.691 & 5.556 & 6.690 & 6.612 & 2.301 \\
\hline 15 & 8.491 & 4.613 & 8.632 & 9.591 & 3.192 & 8.644 & 3.575 & 8.693 & 5.534 & 5.858 & 6.674 & 6.681 & 2.270 \\
\hline 25 & 8.928 & 4.295 & 7.073 & 9.821 & 3.250 & 9.291 & 3.594 & 8.592 & 6.273 & 6.019 & 6.922 & 6.733 & 2.306 \\
\hline 35 & 9.236 & 4.388 & 7.835 & 9.172 & 3.702 & 9.105 & 3.628 & 7.755 & 6.311 & 5.957 & 8.086 & 6.834 & 2.166 \\
\hline 45 & 9.185 & 4.857 & 7.109 & 7.923 & 4.515 & 8.191 & 3.885 & 6.749 & 5.297 & 5.549 & 9.094 & 6.578 & 1.871 \\
\hline 55 & 9.400 & 5.456 & 7.823 & 8.987 & 4.993 & 7.663 & 4.080 & 6.935 & 4.754 & 5.110 & 9.630 & 6.803 & 2.022 \\
\hline 65 & 9.131 & 6.071 & 9.355 & 9.790 & 4.614 & 6.873 & 4.019 & 7.968 & 5.305 & 5.143 & 9.256 & 7.048 & 2.137 \\
\hline 75 & 9.085 & 5.875 & 11.357 & 10.901 & 5.045 & 5.885 & 3.444 & 9.261 & 5.258 & 5.004 & 9.866 & 7.362 & 2.765 \\
\hline 85 & 9.804 & 5.437 & 11.261 & 11.823 & 5.110 & 8.655 & 4.133 & 10.770 & 6.123 & 6.690 & 9.679 & 8.135 & 2.726 \\
\hline 95 & 10.652 & 5.793 & 12.132 & 14.150 & 5.420 & 11.524 & 4.778 & 12.735 & 7.346 & 8.406 & 10.092 & 9.366 & 3.211 \\
\hline 105 & 13.107 & 7.555 & 13.799 & 14.715 & 6.191 & 13.593 & 5.764 & 13.224 & 8.968 & 8.992 & 11.902 & 10.710 & 3.289 \\
\hline 115 & 15.388 & 8.611 & 14.686 & 14.126 & 6.467 & 15.260 & 7.159 & 12.609 & 9.625 & 9.462 & 13.769 & 11.560 & 3.359 \\
\hline 125 & 16.887 & 10.171 & 15.816 & 16.068 & 7.341 & 17.337 & 7.958 & 13.671 & 9.509 & 10.761 & 15.444 & 12.815 & 3.741 \\
\hline 135 & 17.439 & 10.288 & 16.448 & 18.511 & 7.162 & 19.932 & 7.987 & 17.367 & 12.785 & 13.289 & 16.818 & 14.366 & 4.357 \\
\hline 145 & 16.328 & 8.887 & 20.181 & 19.843 & 6.132 & 20.116 & 6.912 & 19.538 & 14.792 & 14.446 & 13.972 & 14.650 & 5.294 \\
\hline 155 & 14.935 & 10.856 & 23.421 & 19.606 & 6.668 & 18.987 & 7.166 & 19.462 & 15.096 & 14.097 & 13.785 & 14.916 & 5.274 \\
\hline 165 & 14.959 & 11.991 & 23.222 & 18.400 & 7.429 & 16.611 & 7.161 & 18.445 & 14.258 & 12.321 & 14.319 & 14.465 & 4.759 \\
\hline 175 & 12.915 & 11.174 & 20.729 & 15.953 & 6.914 & 13.073 & 6.393 & 14.984 & 11.878 & 9.970 & 14.322 & 12.573 & 4.082 \\
\hline 185 & 11.388 & 9.186 & 19.862 & 12.126 & 7.682 & 9.282 & 5.618 & 11.792 & 9.435 & 7.435 & 12.891 & 10.609 & 3.793 \\
\hline 195 & 7.752 & 5.577 & 13.811 & 6.922 & 6.482 & 5.034 & 3.681 & 7.045 & 5.408 & 4.287 & 8.232 & 6.748 & 2.736 \\
\hline 205 & 2.573 & 1.600 & 4.560 & 1.897 & 2.434 & 1.349 & 1.189 & 2.327 & 1.491 & 1.240 & 2.438 & 2.100 & 0.967 \\
\hline
\end{tabular}

The right side of Figure $9(\mathrm{a})$ is the comparison of the mean values of earthquake compressive stresses between Tables 5 and 6 and the corresponding standard deviation. The left side of Figure 9(a) is the comparisons of the mean values of earthquake tensile stresses and the corresponding standard deviation. The data in Tables 7 and 8 (see Appendix B) are provided regarding maximum earthquake tensile stress, mean value, and standard deviation of the $150 \mathrm{~m}$ high chimney when considering vertical eccentricities and neglecting vertical eccentricities. In Figure 9(a), the red and pink columns are, respectively, the mean values of earthquake compressive and tensile stresses considering vertical eccentricities. The blue and green columns are, respectively, the mean values of earthquake compressive and tensile stress neglecting vertical eccentricities. The red and pink lines are, respectively, the standard deviations of different earthquake compressive and tensile stresses considering vertical eccentricities. The blue and green lines are the standard 
TABLE 11: Maximum earthquake tensile stresses of the $210 \mathrm{~m}$ high chimney considering vertical eccentricities.

\begin{tabular}{|c|c|c|c|c|c|c|c|c|c|c|c|c|c|}
\hline \multirow[b]{2}{*}{ High } & \multicolumn{13}{|c|}{ Serial number } \\
\hline & 1 & 2 & 3 & 4 & 5 & 6 & 7 & 8 & 9 & 10 & 11 & Mean & $\begin{array}{l}\text { Standard } \\
\text { deviation }\end{array}$ \\
\hline 5 & -10.262 & -4.948 & -8.135 & -10.034 & -2.895 & -8.930 & -3.943 & -7.722 & -5.298 & -6.667 & -6.588 & -6.857 & 2.424 \\
\hline 15 & -10.435 & -4.938 & -7.568 & -11.181 & -2.919 & -9.723 & -4.201 & -8.217 & -5.552 & -6.907 & -6.881 & -7.138 & 2.630 \\
\hline 25 & -10.935 & -4.554 & -6.246 & -12.106 & -3.241 & -10.269 & -4.221 & -8.691 & -6.122 & -6.946 & -7.151 & -7.317 & 2.884 \\
\hline 35 & -10.553 & -4.145 & -6.472 & -11.522 & -3.273 & -10.373 & -3.642 & -8.527 & -5.875 & -6.486 & -7.779 & -7.150 & 2.868 \\
\hline 45 & -10.408 & -4.240 & -7.468 & -9.756 & -4.018 & -9.579 & -3.551 & -7.277 & -4.746 & -5.330 & -8.867 & -6.840 & 2.562 \\
\hline 55 & -11.024 & -4.832 & -8.860 & -10.900 & -4.600 & -8.365 & -3.709 & -6.914 & -4.711 & -5.920 & -9.001 & -7.167 & 2.610 \\
\hline 65 & -10.567 & -5.284 & -9.795 & -11.400 & -4.375 & -6.960 & -3.870 & -7.157 & -4.987 & -6.342 & -8.445 & -7.198 & 2.563 \\
\hline 75 & -9.261 & -5.017 & -10.066 & -11.198 & -4.483 & -5.807 & -3.879 & -7.801 & -5.100 & -6.042 & -9.195 & -7.077 & 2.520 \\
\hline 85 & -13.145 & -4.857 & -9.754 & -14.902 & -4.693 & -8.210 & -4.959 & -7.609 & -6.291 & -8.202 & -9.445 & -8.370 & 3.332 \\
\hline 95 & -16.522 & -6.118 & -12.903 & -17.6 & -4.622 & -11.390 & -5.345 & -9.8 & -7 & -10.105 & -10.256 & -10 & 4.304 \\
\hline 105 & -17.546 & -7.618 & -15.135 & -17 & -5.666 & -14.323 & -6.034 & -12 & -8.284 & -10.474 & -11 & -11 & 4.327 \\
\hline 115 & -20.278 & -8.779 & -15.214 & -17.6 & -6.720 & -16.912 & -6.769 & -15 & -8 . & -10.066 & -12 . & -12 & 4.725 \\
\hline 125 & -22.597 & -9.647 & 36 & -1 & -6.777 & -19 & -7 & -18 & -9 & 36 & & -1 & 5.641 \\
\hline 135 & -24 & & & & & & & & -1 & -12.573 & -16.906 & -15.798 & 6.393 \\
\hline 145 & -22.866 & -9.103 & -16.355 & -25.713 & -5.767 & -22.516 & -8.095 & -17.358 & -14.228 & -14.451 & -15.153 & -15.600 & 6.365 \\
\hline 155 & -20.992 & -9.940 & -20.354 & -25.657 & -5.673 & -22.139 & -8.594 & -16.513 & -15.972 & -14.672 & -14.746 & -15.932 & 6.137 \\
\hline 165 & -19.689 & -11.736 & -21.039 & -25.636 & -7.114 & -20.421 & -9.126 & -15.506 & -15.183 & -13.670 & -12.456 & -15.598 & 5.594 \\
\hline 175 & -17.762 & -11.194 & -21.276 & -21.932 & -6.327 & -16.354 & -8.317 & -13.811 & -12.043 & -11.622 & -13.407 & -14.004 & 4.944 \\
\hline 185 & -13.414 & -8.601 & -17.871 & -15.897 & -6.273 & -11.122 & -6.563 & -10.575 & -8.266 & -8.356 & -12.082 & -10.820 & 3.745 \\
\hline 195 & -7.845 & -4.509 & -10.141 & -8.223 & -4.973 & -5.357 & -3.606 & -5.460 & -4.672 & -4.489 & -7.163 & -6.040 & 2.015 \\
\hline 205 & -1.591 & -0.770 & -1.794 & -1.524 & -1.424 & -0.845 & -0.694 & -0.972 & -0.819 & -0.753 & -1.387 & -1.143 & 0.403 \\
\hline
\end{tabular}

TABLE 12: Maximum earthquake tensile stresses of the $210 \mathrm{~m}$ high chimney ignoring vertical eccentricities.

\begin{tabular}{|c|c|c|c|c|c|c|c|c|c|c|c|c|c|}
\hline \multirow[b]{2}{*}{ High } & \multicolumn{13}{|c|}{ Serial number } \\
\hline & 1 & 2 & 3 & 4 & 5 & 6 & 7 & 8 & 9 & 10 & 11 & Mean & $\begin{array}{l}\text { Standard } \\
\text { deviation }\end{array}$ \\
\hline 5 & -7.404 & -4.719 & -8.533 & -8.527 & -3.335 & -8.004 & -3.635 & -7.965 & -6.483 & -5 & -7 & 28 & 1.923 \\
\hline 15 & -7.867 & -4.672 & -7.619 & -9.499 & -3.416 & -8.788 & -3.696 & -8.663 & -6.613 & -6.051 & -7.548 & -6.767 & \\
\hline 25 & -8.776 & -4.683 & -8.208 & -10.373 & -3.163 & -9.459 & -3.540 & -9.161 & -6.331 & -6.333 & -6.843 & -6.988 & 2.443 \\
\hline 35 & -9.086 & -4.199 & -8.700 & -10.468 & -3.866 & -9.371 & -3.766 & -8.596 & -5.128 & -6.099 & -7.874 & & \\
\hline 45 & -8 & -4.540 & -7.3 & -9 & -4 & -8 & -4.033 & -7.092 & -4 & -5 & -8 . & & \\
\hline 55 & -7.768 & -5.168 & -8.978 & $-\varepsilon$ & -4 & -7.902 & -4.170 & -6.826 & -4.667 & -5.156 & -9.280 & & \\
\hline 65 & -8.262 & -5.869 & -8.851 & -9.6 & -4.784 & -7.242 & -4.073 & -7.791 & -5.180 & -5.147 & -9.472 & & 08 \\
\hline 75 & -8.876 & -5.860 & -9.759 & -10.681 & -4.735 & -6.168 & -3.488 & -8.404 & -5.163 & -4.789 & -9.311 & & 44 \\
\hline 85 & -9.957 & -5.203 & -10.615 & -12.112 & -5.577 & -8.535 & -3.543 & -10.392 & -6.100 & -6.789 & -8.921 & 77 & 03 \\
\hline 95 & -11.990 & -6.905 & -12.809 & 58 & -5.783 & -11.466 & -4.556 & -12.103 & -7.473 & -8.771 & -9.768 & 53 & 052 \\
\hline 105 & -13.475 & -8.542 & -13.539 & -14.303 & -6.060 & -13.615 & -5.865 & -12.736 & -8.416 & -9.708 & -11.819 & -10.734 & 3.137 \\
\hline 115 & -14.847 & -9.219 & -14.785 & -14.387 & -6.629 & -15.528 & -7.442 & -12.490 & -8.892 & -9.946 & -13.041 & -11.564 & .232 \\
\hline 125 & -16.430 & -10.839 & -14.144 & -16.638 & -7.599 & -17.232 & -8.242 & -15.041 & -11.332 & -11.355 & -15.373 & -13 & \\
\hline 135 & -17.538 & -10.834 & -18.645 & -19 & -6.946 & -20.560 & -7.990 & -17 & -13 & -13.107 & -15 & -1 & 4.638 \\
\hline 145 & -16.080 & -8.417 & -21.186 & -20.686 & -6.343 & -20.739 & -7.896 & -19.356 & -13.220 & -13.720 & -12.230 & -14.534 & 5.500 \\
\hline 155 & -18.273 & -9.907 & -21.025 & -21.991 & -5.937 & -19.264 & -8.263 & -19.261 & -14.030 & -12.955 & -13.363 & -14.933 & 5.417 \\
\hline 165 & -18.640 & -11.394 & -23.870 & -20.157 & -6.959 & -17.581 & -8.305 & -17.337 & -13.363 & -11.784 & -15.212 & & \\
\hline 175 & -15.885 & -11.241 & -21.453 & -15.522 & -7.398 & -14.219 & -7.484 & -14.848 & -11.109 & -9.557 & -15.198 & -13.083 & 4.197 \\
\hline 185 & -11.686 & -8.918 & -19.105 & -12.072 & -6.373 & -10.024 & -5.830 & -10.987 & -8.906 & -6.633 & -12.945 & -10.316 & 3.779 \\
\hline 195 & -7.186 & -5.468 & -13.557 & -7.196 & -5.199 & -5.307 & -3.738 & -6.277 & -5.492 & -3.635 & -8.202 & -6.478 & 2.734 \\
\hline 205 & -2.180 & -1.625 & -4.540 & -2.291 & -2.251 & -1.383 & -1.265 & -2.016 & -1.692 & -1.025 & -2.601 & -2.079 & 0.950 \\
\hline
\end{tabular}

deviations of different earthquake compressive and tensile stresses neglecting vertical eccentricities. Figure 9(b) shows the case of the $210 \mathrm{~m}$ high chimney (data in Tables 9-12).

Figure 9 shows that the earthquake normal stresses increase evidently when considering vertical eccentricities. Significant differences of the maximum earthquake normal stress are observed under different seismic waves actions.

Figure 10 is the boxplot of the maximum earthquake compressive stress distribution at different cross sections of
$150 \mathrm{~m}$ and $210 \mathrm{~m}$ high chimneys under different seismic wave actions when considering eccentricities. They show the mean value, minimum, maximum, and $25 \%-75 \%$ of earthquake compressive stresses. The distribution characteristics of the earthquake compressive stress data are also shown in the figures. The stress distributions near the bottom of the chimney are relatively intensive, whereas those at the middle and upper parts of the chimney are relatively scattered. 


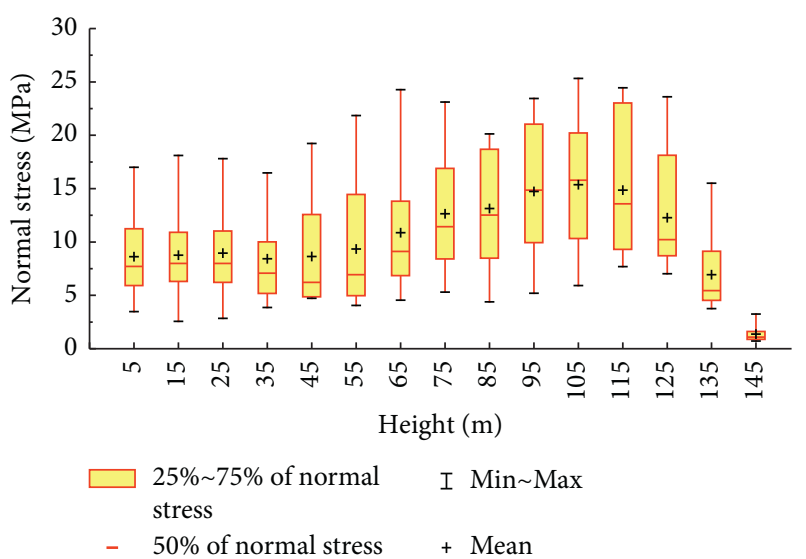

(a)

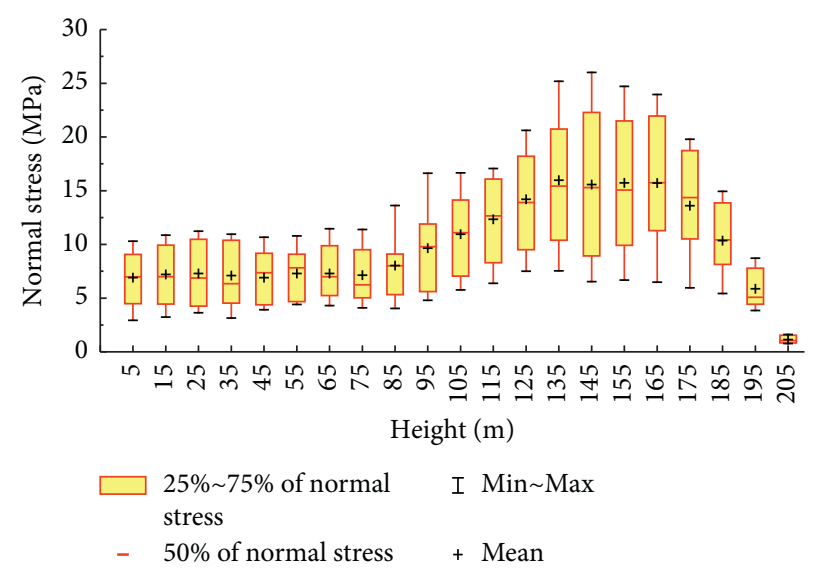

(b)

FIGURE 10: Boxplot of the compressive stress distribution of chimney considering eccentricities: (a) $150 \mathrm{~m}$ high chimney; (b) $210 \mathrm{~m}$ high chimney.

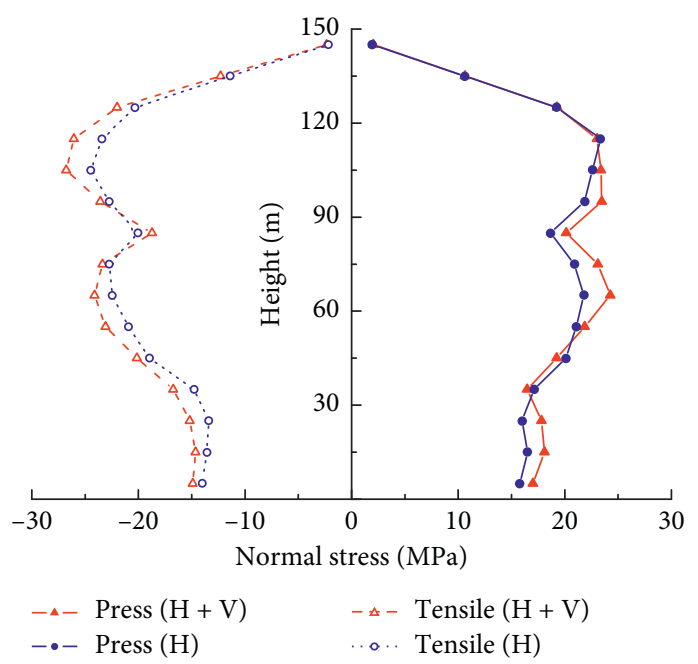

(a)

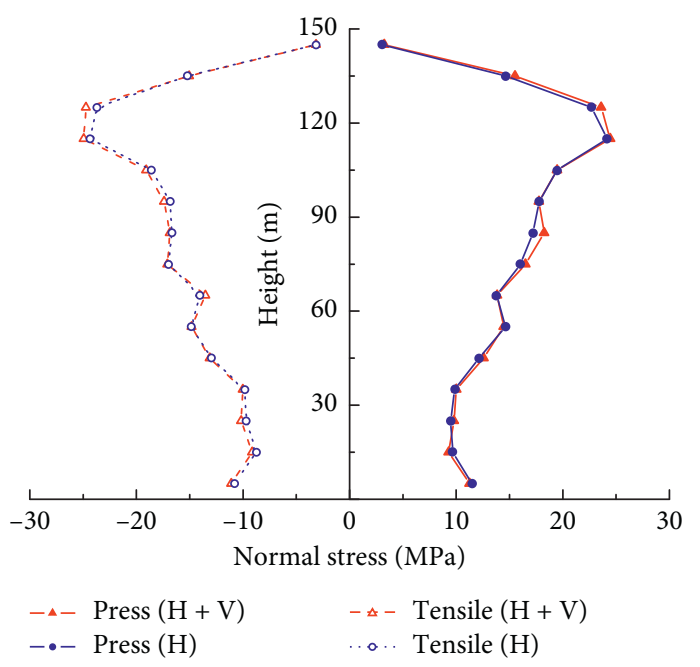

(c)

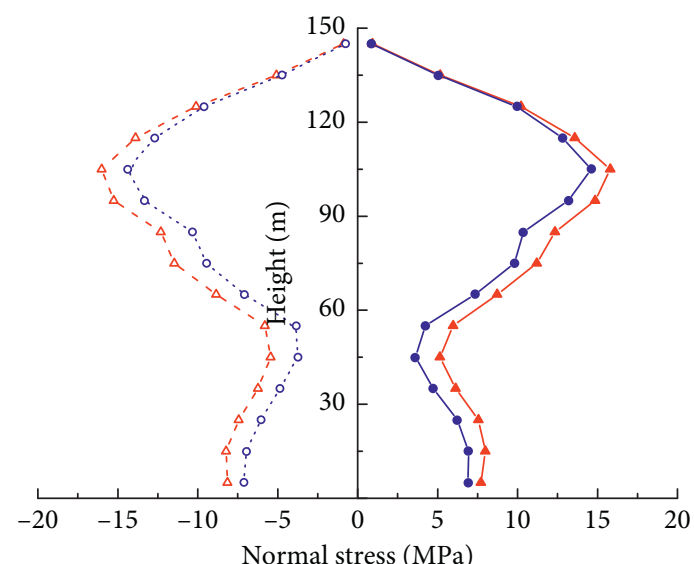

$-\Delta-$ Press $(\mathrm{H}+\mathrm{V}) \quad-\_-$Tensile $(\mathrm{H}+\mathrm{V})$

(b)

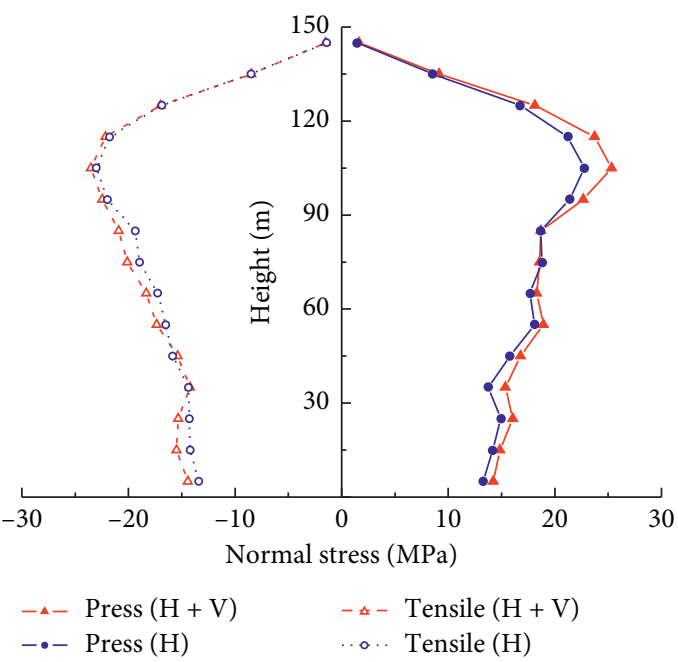

(d)

FIgURE 11: Spatial distributions of maximum earthquake normal stresses at different cross sections for the $150 \mathrm{~m}$ high chimney under two types of seismic load applied for each of the four earthquake wave actions: (a) Landers wave (No. 1); (b) Loma Prieta wave (No. 2); (c) Borrego wave (No. 3); (d) Chichi wave (No. 4). 


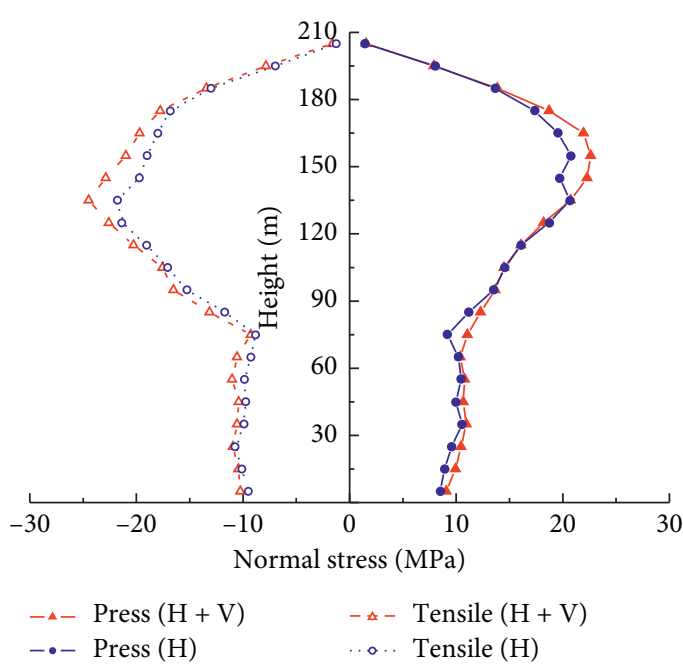

(a)

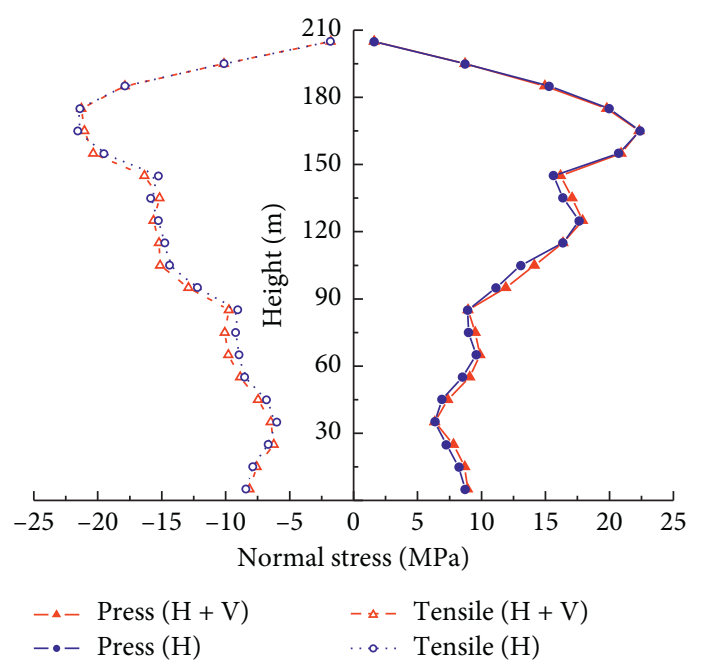

(c)

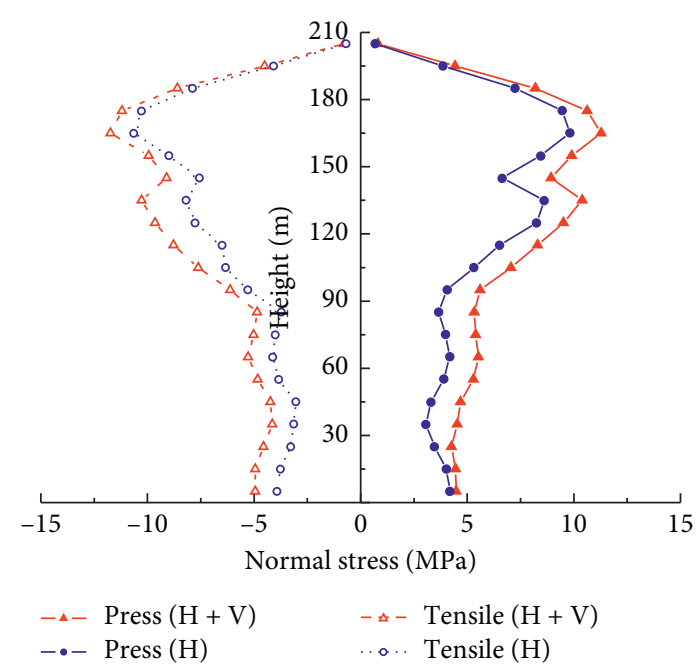

(b)

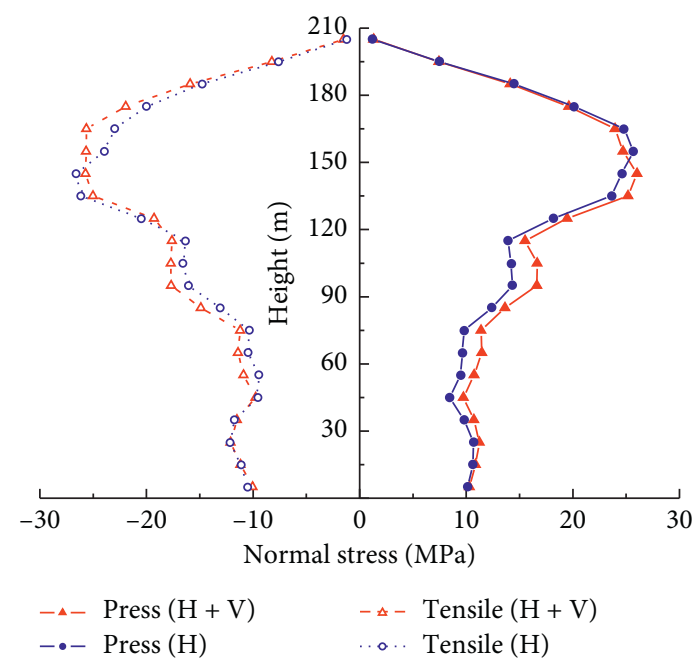

(d)

FIGURE 12: Spatial distributions of maximum earthquake normal stresses at different cross sections for the $210 \mathrm{~m}$ high chimney under two types of seismic load applied for each of the four earthquake wave actions: (a) Landers wave (No. 1); (b) Loma Prieta wave (No. 2); (c) Borrego wave (No. 3); (d) Chichi wave (No. 4).

The results studied above show that significant differences of maximum earthquake normal stress under different earthquake wave actions. The comparisons demonstrate that the conventional results (eccentricities neglected) might be less than their actual tensile/compressive stresses in the seismic control cross section of the chimneys under the actions of several specific earthquake waves. The calculation results show that eccentricities between the spatial discrete nodes and the corresponding centroids of investigated lumps should be considered in earthquake response of tall RC chimneys to obtain accurate calculation results.

5.2.2. Effects of Vertical Earthquake. The phenomena of eccentricities are considered to study the effect of vertical earthquake on earthquake normal stresses. Two types of seismic load are applied for each of the four earthquake waves. In the first case, the combined horizontal and vertical earthquake waves (see red lines in Figures 11 and 12) are inputted. In the second case, only the horizontal earthquake wave (see blue lines in Figures 11 and 12) is inputted.

For the $150 \mathrm{~m}$ high chimney, Figure 11 shows that the peak normal tensile stress increases by $4 \%$ for the Landers wave (No. 1) and 10\% for the Loma Prieta wave (No. 2) if vertical earthquake waves are considered. The peak normal compressive stress increases by $7 \%$ for the Loma Prieta wave (No. 2) and $10 \%$ for the Chichi wave (No. 4) if vertical earthquake waves are considered.

For the $210 \mathrm{~m}$ high chimney, Figure 12 shows that the peak normal tensile stress increases by $12 \%$ for the Landers wave (No. 1) and $9 \%$ for the Loma Prieta wave (No. 2) if vertical earthquake waves are considered. The peak normal compressive stress increases by $9 \%$ for Landers wave (No. 1) and $13 \%$ for Loma Prieta wave (No. 2) if vertical earthquake waves are considered. 


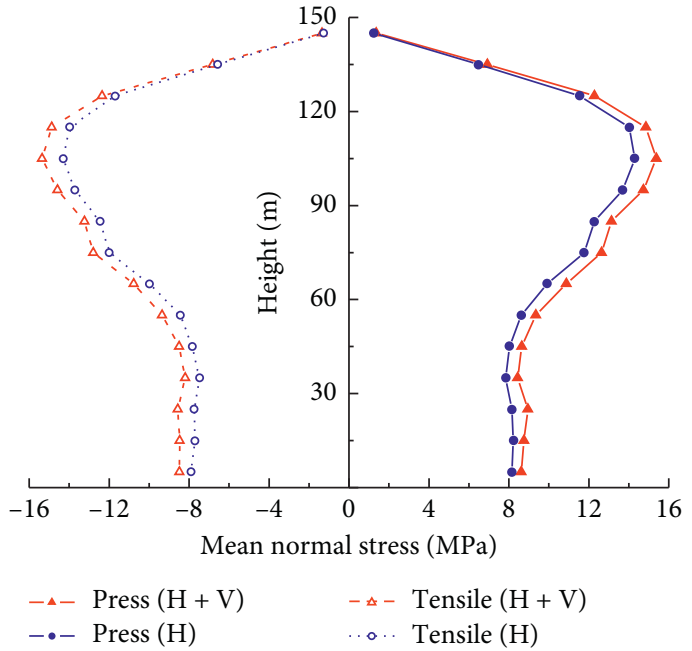

(a)

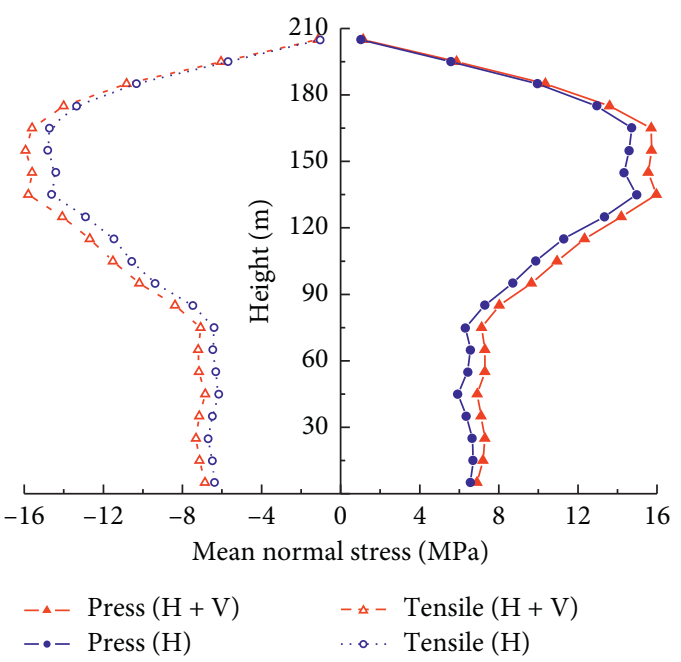

(b)

FIGURE 13: Comparison curve of the mean value of maximum earthquake normal stresses for chimneys under two types of seismic load: (a) $150 \mathrm{~m}$ high chimney; (b) $210 \mathrm{~m}$ high chimney.

TABle 13: Maximum earthquake compressive stresses of the $150 \mathrm{~m}$ high chimney when only horizontal seismic acceleration is inputted.

\begin{tabular}{|c|c|c|c|c|c|c|c|c|c|c|c|c|c|}
\hline \multirow{2}{*}{ High } & \multicolumn{13}{|c|}{ Serial number } \\
\hline & 1 & 2 & 3 & 4 & 5 & 6 & 7 & 8 & 9 & 10 & 11 & Mean & Standard deviation \\
\hline 5 & 15.762 & 6.884 & 11.475 & 13.226 & 2.984 & 9.720 & 5.314 & 7.104 & 3.694 & 6.267 & 7.235 & 8.151 & 3.986 \\
\hline 15 & 16.533 & 6.912 & 9.673 & 14.154 & 2.374 & 10.375 & 5.697 & 7.298 & 3.395 & 6.244 & 7.812 & 8.224 & 4.261 \\
\hline 25 & 15.970 & 6.204 & 9.464 & 14.907 & 2.194 & 10.292 & 5.644 & 6.853 & 3.049 & 6.014 & 9.059 & 8.150 & 4.379 \\
\hline 35 & 17.119 & 4.713 & 9.862 & 13.772 & 2.836 & 8.412 & 4.903 & 6.279 & 4.110 & 5.139 & 9.057 & 7.837 & 4.407 \\
\hline 45 & 20.107 & 3.593 & 12.133 & 15.772 & 4.133 & 5.642 & 4.755 & 5.276 & 4.437 & 3.707 & 8.936 & 8.045 & 5.603 \\
\hline 55 & 21.071 & 4.229 & 14.646 & 18.041 & 3.645 & 6.161 & 5.083 & 6.183 & 3.713 & 3.242 & 8.740 & 8.614 & 6.337 \\
\hline 65 & 21.786 & 7.321 & 13.780 & 17.612 & 3.645 & 10.790 & 6.299 & 8.381 & 4.823 & 5.491 & 9.217 & 9.922 & 5.686 \\
\hline 75 & 20.897 & 9.792 & 16.022 & 18.742 & 4.307 & 15.863 & 7.209 & 10.533 & 5.855 & 8.858 & 11.386 & 11.769 & 5.406 \\
\hline 85 & 18.671 & 10.349 & 17.184 & 18.626 & 3.973 & 18.579 & 7.799 & 11.399 & 5.396 & 11.049 & 12.025 & 12.277 & 5.361 \\
\hline 95 & 21.849 & 13.139 & 17.782 & 21.304 & 4.313 & 19.716 & 8.952 & 13.522 & 5.751 & 12.327 & 12.051 & 13.701 & 5.966 \\
\hline 105 & 22.592 & 14.578 & 19.457 & 22.671 & 4.985 & 19.364 & 9.133 & 14.541 & 6.688 & 12.095 & 11.287 & 14.308 & 6.136 \\
\hline 115 & 23.369 & 12.785 & 24.161 & 21.098 & 7.016 & 16.249 & 8.339 & 12.902 & 7.520 & 11.069 & 9.754 & 14.024 & 6.313 \\
\hline 125 & 19.263 & 9.922 & 22.706 & 16.703 & 7.430 & 11.274 & 6.289 & 9.926 & 7.222 & 8.303 & 7.947 & 11.544 & 5.502 \\
\hline 135 & 10.624 & 5.025 & 14.653 & 8.506 & 5.419 & 5.190 & 3.297 & 5.773 & 4.065 & 4.181 & 4.662 & 6.490 & 3.436 \\
\hline 145 & 1.946 & 0.838 & 3.020 & 1.463 & 1.236 & 0.789 & 0.615 & 1.260 & 0.848 & 0.766 & 0.892 & 1.243 & 0.705 \\
\hline
\end{tabular}

TABLE 14: Maximum earthquake tensile stresses of the $150 \mathrm{~m}$ high chimney when only horizontal seismic acceleration is inputted.

\begin{tabular}{|c|c|c|c|c|c|c|c|c|c|c|c|c|c|}
\hline \multirow[b]{2}{*}{ High } & \multicolumn{13}{|c|}{ Serial number } \\
\hline & 1 & 2 & 3 & 4 & 5 & 6 & 7 & 8 & 9 & 10 & 11 & Mean & $\begin{array}{l}\text { Standard } \\
\text { deviation }\end{array}$ \\
\hline 5 & -14.019 & -7.073 & -10.794 & -13.376 & -3.065 & -9.883 & -5.107 & -7.404 & -2.917 & -6.109 & -7.146 & -7.899 & 3.748 \\
\hline 15 & -13.568 & -6.946 & -8.764 & -14.184 & -2.128 & -10.529 & -5.319 & -7.538 & -2.438 & -6.015 & -7.459 & -7.717 & 3.918 \\
\hline 25 & -13.396 & -6.049 & -9.673 & -14.268 & -2.217 & -10.586 & -5.134 & -7.319 & -2.751 & -5.799 & -7.994 & -7.744 & 3.943 \\
\hline 35 & -14.760 & -4.852 & -9.829 & -14.309 & -2.644 & -8.895 & -4.731 & -6.290 & -3.085 & -5.040 & -7.879 & -7.483 & 4.145 \\
\hline 45 & -18.971 & -3.749 & -12.950 & -15.797 & -3.562 & -6.153 & -4.989 & -5.575 & -3.317 & -3.663 & -7.614 & -7.849 & 5.499 \\
\hline 55 & -20.940 & -3.856 & -14.872 & -16.458 & -3.938 & -5.793 & -5.151 & -5.917 & -3.675 & -3.466 & -8.690 & -8.432 & 6.123 \\
\hline 65 & -22.465 & -7.073 & -14.037 & -17.207 & -3.647 & -10.650 & -6.376 & -8.108 & -4.479 & -5.484 & -10.224 & -9.977 & 5.836 \\
\hline 75 & -22.721 & -9.433 & -16.977 & -18.920 & -4.644 & -15.423 & -7.684 & -10.420 & -5.601 & -8.588 & -11.544 & -11.996 & 5.779 \\
\hline 85 & -20.043 & -10.301 & -16.678 & -19.349 & -4.152 & -17.961 & -8.200 & -11.508 & -4.973 & -11.015 & -12.732 & -12.447 & 5.513 \\
\hline 95 & -22.737 & -13.287 & -16.842 & -21.924 & -5.111 & -19.726 & -9.137 & -12.996 & -4.815 & -11.834 & -12.481 & -13.717 & 6.121 \\
\hline 105 & -24.485 & -14.367 & -18.594 & -22.963 & -5.152 & -18.972 & -9.762 & -13.993 & -5.724 & -11.670 & -11.579 & -14.297 & 6.413 \\
\hline 115 & -23.410 & -12.647 & -24.355 & -21.682 & -6.705 & -15.693 & -8.900 & -12.975 & -6.598 & -11.093 & -9.727 & -13.980 & 6.490 \\
\hline 125 & -20.313 & -9.584 & -23.734 & -16.823 & -7.219 & -10.906 & -6.540 & -9.631 & -6.598 & -8.641 & -8.727 & -11.701 & 5.879 \\
\hline 135 & -11.408 & -4.711 & -15.196 & -8.484 & -5.553 & -4.981 & -3.266 & -5.171 & -4.017 & -4.446 & -5.039 & -6.570 & 3.671 \\
\hline 145 & -2.166 & -0.757 & -3.138 & -1.419 & -1.330 & -0.772 & -0.624 & -1.151 & -0.790 & -0.775 & -0.950 & -1.261 & 0.764 \\
\hline
\end{tabular}


TABLE 15: Maximum earthquake compressive stresses of the $210 \mathrm{~m}$ high chimney when only horizontal seismic acceleration is inputted.

\begin{tabular}{|c|c|c|c|c|c|c|c|c|c|c|c|c|c|}
\hline \multirow{2}{*}{ High } & \multicolumn{13}{|c|}{ Serial number } \\
\hline & 1 & 2 & 3 & 4 & 5 & 6 & 7 & 8 & 9 & 10 & 11 & Mean & Standard deviation \\
\hline 5 & 8.481 & 4.199 & 8.705 & 10.156 & 2.007 & 9.332 & 3.272 & 7.522 & 5.873 & 6.495 & 6.213 & 6.569 & 2.599 \\
\hline 15 & 8.901 & 4.019 & 8.216 & 10.622 & 2.225 & 10.012 & 3.285 & 8.055 & 5.978 & 6.514 & 5.906 & 6.703 & 2.746 \\
\hline 25 & 9.582 & 3.469 & 7.243 & 10.684 & 2.446 & 10.362 & 3.266 & 8.297 & 5.919 & 6.143 & 5.912 & 6.666 & 2.869 \\
\hline 35 & 10.568 & 3.052 & 6.345 & 9.797 & 2.526 & 9.397 & 2.767 & 7.913 & 5.484 & 5.128 & 6.954 & 6.357 & 2.870 \\
\hline 45 & 9.972 & 3.302 & 6.902 & 8.454 & 3.223 & 7.488 & 2.873 & 7.388 & 4.133 & 4.051 & 7.458 & 5.931 & 2.467 \\
\hline 55 & 10.485 & 3.886 & 8.502 & 9.475 & 3.529 & 7.237 & 3.392 & 6.915 & 4.759 & 4.188 & 8.276 & 6.422 & 2.573 \\
\hline 65 & 10.190 & 4.154 & 9.585 & 9.633 & 3.223 & 6.894 & 3.521 & 6.782 & 5.247 & 4.515 & 8.447 & 6.563 & 2.599 \\
\hline 75 & 9.191 & 3.988 & 8.965 & 9.777 & 3.536 & 5.854 & 3.329 & 6.980 & 4.994 & 4.741 & 8.090 & 6.313 & 2.395 \\
\hline 85 & 11.177 & 3.643 & 8.928 & 12.420 & 3.799 & 7.406 & 3.792 & 8.005 & 5.956 & 6.387 & 8.570 & 7.280 & 2.943 \\
\hline 95 & 13.516 & 4.035 & 11.145 & 14.322 & 3.448 & 10.454 & 4.424 & 9.272 & 7.536 & 7.673 & 9.883 & 8.701 & 3.683 \\
\hline 105 & 14.580 & 5.302 & 13.069 & 14.196 & 4.576 & 12.836 & 5.224 & 10.651 & 8.796 & 8.504 & 10.711 & 9.859 & 3.671 \\
\hline 115 & 16.062 & 6.498 & 16.367 & 13.919 & 5.366 & 15.006 & 6.185 & 13.698 & 10.445 & 8.645 & 11.724 & 11.265 & 4.087 \\
\hline 125 & 18.730 & 8.256 & 17.638 & 18.152 & 5.275 & 19.078 & 7.159 & 16.475 & 11.612 & 10.651 & 13.545 & 13.325 & 5.028 \\
\hline 135 & 20.661 & 8.608 & 16.365 & 23.615 & 5.444 & 21.778 & 8.219 & 17.456 & 14.630 & 14.181 & 13.650 & 14.964 & 5.838 \\
\hline 145 & 19.716 & 6.626 & 15.624 & 24.576 & 4.835 & 21.610 & 7.150 & 16.670 & 14.439 & 14.995 & 11.521 & 14.342 & 6.352 \\
\hline 155 & 20.779 & 8.409 & 20.741 & 25.679 & 4.079 & 20.345 & 6.788 & 16.586 & 13.115 & 14.038 & 9.833 & 14.581 & 6.862 \\
\hline 165 & 19.550 & 9.803 & 22.386 & 24.808 & 5.578 & 18.092 & 7.307 & 16.231 & 12.737 & 12.603 & 13.035 & 14.739 & 6.095 \\
\hline 175 & 17.347 & 9.451 & 19.978 & 20.117 & 5.357 & 14.149 & 7.215 & 13.845 & 10.595 & 11.112 & 13.379 & 12.959 & 4.840 \\
\hline 185 & 13.642 & 7.253 & 15.301 & 14.461 & 5.160 & 9.390 & 5.906 & 9.742 & 7.723 & 8.592 & 12.240 & 9.946 & 3.487 \\
\hline 195 & 7.997 & 3.857 & 8.696 & 7.489 & 4.402 & 4.434 & 3.330 & 4.899 & 4.067 & 4.728 & 7.289 & 5.563 & 1.906 \\
\hline 205 & 1.474 & 0.668 & 1.583 & 1.222 & 1.160 & 0.650 & 0.567 & 0.936 & 0.698 & 0.824 & 1.336 & 1.011 & 0.360 \\
\hline
\end{tabular}

TABle 16: Maximum earthquake tensile stresses of the $210 \mathrm{~m}$ high chimney when only horizontal seismic acceleration is inputted.

\begin{tabular}{|c|c|c|c|c|c|c|c|c|c|c|c|c|c|}
\hline \multirow[b]{2}{*}{ High } & \multicolumn{13}{|c|}{ Serial number } \\
\hline & 1 & 2 & 3 & 4 & 5 & 6 & 7 & 8 & 9 & 10 & 11 & Mean & $\begin{array}{l}\text { Standard } \\
\text { deviation }\end{array}$ \\
\hline 5 & -9.499 & -3.914 & -8.402 & -10.528 & -2.271 & -8.311 & -3.147 & -6.884 & -5.485 & -5.603 & -6.195 & -6.385 & 2.643 \\
\hline 15 & -10.088 & -3.759 & -7.888 & -11.120 & -2.170 & -9.016 & -3.276 & -7.374 & -5.517 & -5.617 & -5.575 & -6.491 & 2.872 \\
\hline 25 & -10.735 & -3.268 & -6.696 & -12.154 & -2.343 & -9.816 & -3.359 & -8.020 & -5.630 & -5.495 & -6.296 & -6.710 & 3.196 \\
\hline 35 & -9.917 & -3.148 & -6.027 & -11.745 & -2.324 & -9.532 & -2.986 & -7.852 & -5.311 & -5.431 & -7.037 & -6.483 & 3.071 \\
\hline 45 & -9.763 & -3.035 & -6.814 & -9.538 & -3.218 & -7.901 & -3.112 & -7.034 & -4.432 & -4.657 & -8.188 & -6.154 & 2.563 \\
\hline 55 & -9.887 & -3.853 & -8.522 & -9.456 & -3.515 & -6.972 & -3.159 & -6.434 & -4.759 & -4.555 & -8.436 & -6.323 & 2.486 \\
\hline 65 & -9.276 & -4.106 & -8.968 & -10.471 & -3.061 & -6.145 & -3.460 & -7.597 & -5.049 & -4.824 & -8 . & & 550 \\
\hline 75 & -8.813 & -4.006 & -9.2 & -10.3 & - & -5 & -3 . & -8 & -5 & -4.562 & -8 & & 93 \\
\hline 85 & -11.696 & -3.733 & -9.048 & -13.089 & -3.214 & -7.460 & -4.127 & -7.880 & -6.340 & -6.498 & -9.220 & 82 & 3.172 \\
\hline 95 & -15.283 & -5.286 & -12.218 & -16 & -3.427 & -10.971 & -4.6 & -9.692 & -7 & -8.267 & -10 & -9 & .147 \\
\hline 105 & 0 & -6.333 & -14 & -16 . & -4.330 & -13.582 & -5.322 & -11.064 & -8.223 & -8.519 & -10 . & -10.566 & 4.430 \\
\hline 115 & -19.059 & -6.495 & -14.769 & -16.340 & -5.136 & -15.559 & -5.968 & -14.179 & -8.929 & -7.669 & -12.054 & -11.469 & 4.823 \\
\hline 125 & -21.359 & -7.756 & -15.261 & -20 . & -5.311 & -17.463 & -6.259 & -17.193 & -9.471 & -8.103 & -13.228 & -12.900 & 5.807 \\
\hline 135 & -21.802 & -8.174 & -15.876 & -26.142 & -5.335 & -20.549 & -7.745 & -18.417 & -11.458 & -11.799 & -13.529 & -14.621 & 6.555 \\
\hline 145 & -19.722 & -7.568 & -15.281 & -26.594 & -4.215 & -21.400 & -7.706 & -16.488 & -13.112 & -13.520 & -12.850 & -14.405 & 6.567 \\
\hline 155 & -18.995 & -9.012 & -19.516 & -23.940 & -4.076 & -21.179 & -8.472 & -16.200 & -15.026 & -13.612 & -12.953 & -14.816 & 5.995 \\
\hline 165 & -18.022 & -10.638 & -21.577 & -22.969 & -5.468 & -19.116 & -8.724 & -16.437 & -14.438 & -12.906 & -11.733 & -14.730 & 5.466 \\
\hline 175 & -16.832 & -10.263 & -21.403 & -20.010 & -5.569 & -15.119 & -7.902 & -14.741 & -11.533 & -11.518 & -11.998 & -13.353 & 4.844 \\
\hline 185 & -13.024 & -7.875 & -17.879 & -14.764 & -5.138 & -10.190 & -5.783 & -11.224 & -8.565 & -8.835 & -10.257 & -10.321 & 3.791 \\
\hline 195 & -6.944 & -4.092 & -10.140 & & -4.379 & & & -5.887 & & -4.741 & -5.925 & & 1.956 \\
\hline 205 & -1.261 & -0.689 & -1.797 & -1.221 & -1.265 & -0.696 & -0.591 & -1.091 & -0.865 & -0.805 & -1.125 & -1.037 & 0.353 \\
\hline
\end{tabular}

Figure 13 shows the spatial comparison curves of the mean values of the maximum normal earthquake stresses for the $150 \mathrm{~m}$ and $210 \mathrm{~m}$ high chimneys under two types of seismic load. Figure 13(a) is obtained from the average values of Tables 5, 7, 13, and 14. Figure 13(b) is drawn from the mean values of Tables 9, 11, 15, and 16. Figure 13 shows that the normal stress of the chimney can be increased considering the vertical seismic acceleration.
The results studied above show that the vertical ground motion should not be neglected, especially for tall RC chimneys built on rock sites or soft rock sites.

\section{Conclusions}

A numerical algorithm that can consider the existing phenomena of eccentricities is presented to calculate the earthquake responses of tall RC chimneys. The numerical results 
demonstrate that the tensile and compressive stresses may increase in the seismic control cross sections of the chimneys under the actions of several specific earthquake waves when existing eccentricities are considered. The phenomena of eccentricities should be considered to obtain accurate calculation results of earthquake responses for the seismic designs of tall RC chimneys. The maximum normal stresses of earthquake response appear within the upper half of the chimneys, and their values are considerably larger than those within the lower half of the chimneys. Vertical ground motion should not be neglected, especially for chimneys on rock sites and soft rock sites.

\section{Appendix}

\section{A. Corresponding Relations}

For simplicity in deriving the stability condition, we assume that $(\mathrm{EI})_{l}=(\mathrm{EI}), h_{j}=h$, and $\alpha_{j}=\alpha$ for all segments and $m_{i}=m$ and $J_{i}=J$ for all investigated lumps. Axial force $N_{l}$ is omitted in $K_{1 l}, K_{2 l}$, and $K_{3 l}$. Eccentric phenomena are neglected in equation (9). Let $z_{c i}$ be zero. The vertical governing equations are decoupled from the governing equations of transverse and rotational deformations. Thus, we study the equations coupling transverse and rotational deformations to provide the stability condition for the method in this work.

On the basis of the aforementioned assumption, the corresponding equations between the governing equations of Timoshenko theory and the proposed method can be expressed as follows:

$$
\begin{aligned}
m \frac{\partial^{2} u_{i}}{\partial t^{2}} & =V_{l}-V_{l-1} \Longleftrightarrow \rho_{0} A_{0} \frac{\partial^{2} u}{\partial t^{2}}=\frac{\partial V}{\partial z}, \\
V_{i} & =K\left(u_{i+1}-u_{i}-\frac{\theta_{i}+\theta_{i+1}}{2} h\right) \Longleftrightarrow V=\mathrm{GA}_{s}\left(\frac{\partial u}{\partial z}-\varphi\right),
\end{aligned}
$$

$$
\begin{gathered}
J \frac{\partial^{2} \varphi_{i}}{\partial t^{2}}=\left(M_{l}-M_{l-1}\right)+h\left(\frac{V_{l}+V_{l-1}}{2}\right) \Longleftrightarrow \rho_{0} I \frac{\partial^{2} \varphi}{\partial t^{2}}=\frac{\partial M}{\partial z}+V, \\
M_{i}=(\mathrm{EI}) \frac{\theta_{i+1}-\theta_{i}}{h} \Longleftrightarrow M=\mathrm{EI} \frac{\partial \varphi}{\partial z},
\end{gathered}
$$

where $K=\left(12(\mathrm{EI}) / h^{3}\right)(1 /(1+2 \alpha))$.

On the basis of the aforementioned corresponding relations of equations, the corresponding relations between the coefficients used in the continuum Timoshenko beam theory and those used in the proposed method are

$$
\begin{aligned}
& \rho_{0} A_{0} \Longleftrightarrow \frac{m}{h}, \\
& \mathrm{GA}_{s} \Longleftrightarrow K h, \\
& \rho_{0} I \Longleftrightarrow \frac{J}{h}, \\
& \mathrm{EI} \Longleftrightarrow(\mathrm{EI}) .
\end{aligned}
$$

Therefore, we have

$$
\begin{aligned}
& C_{0}^{2}=\frac{E}{\rho_{0}}=\frac{\mathrm{EI}}{\rho_{0} I} \Longleftrightarrow \frac{(\mathrm{EI})}{J / h}=\frac{(\mathrm{EI}) h}{J}, \\
& R^{2}=\frac{I}{A_{0}}=\frac{\rho_{0} I}{\rho_{0} A_{0}} \Longleftrightarrow \frac{J / h}{m / h}=\frac{J}{m}, \\
& C_{Q}^{2}=\frac{\mathrm{GA}_{s}}{\rho_{0} A_{0}} \Longleftrightarrow \frac{K h}{m / h}=\frac{12(\mathrm{EI})}{m h(1+2 \alpha)},
\end{aligned}
$$

where $I$ is the moment of inertia of the cross-sectional area with respect to the neutral axis.

A.1. Stability Condition Based on Timoshenko Beam Model The flexural wave equation of Timoshenko beam is

$$
\frac{\partial^{2} u}{\partial^{2} t}+C_{0}^{2} R^{2} \frac{\partial^{4} u}{\partial^{4} z}-R^{2}\left(1+\frac{C_{0}^{2}}{C_{Q}^{2}}\right) \frac{\partial^{4} u}{\partial^{2} z \partial^{2} t}+\frac{R^{2}}{C_{Q}^{2}} \frac{\partial^{4} u}{\partial^{4} t}=0
$$

where $C_{0}^{2}=\left(E / \rho_{0}\right), R^{2}=\left(I / A_{0}\right)$, and $C_{Q}^{2}=\left(\mathrm{GA}_{s} / \rho_{0} A_{0}\right) ; E$ and $G$ are the elastic and shear moduli of the beam, respectively; $\rho_{0}$ is the mass density; $A_{0}$ is the cross-sectional area; and $A_{s}$ is the effective cross-sectional area for the shear deformation of the beam.

The finite difference formula of equation (A.9) is

$$
\begin{aligned}
& \frac{1}{\Delta t^{2}}\left(u_{i}^{t+\Delta t}-2 u_{i}^{t}+u_{i}^{t-\Delta t}\right)+\frac{C_{0}^{2} R^{2}}{h^{4}}\left[\left(u_{i+2}^{t}-2 u_{i+1}^{t}+u_{i}^{t}\right)-2\left(u_{i+1}^{t}-2 u_{i}^{t}+u_{i-1}^{t}\right)+\left(u_{i}^{t}-2 u_{i-1}^{t}+u_{i-2}^{t}\right)\right] \\
& -R^{2}\left(1+\frac{C_{0}^{2}}{C_{Q}^{2}}\right) \cdot \frac{1}{h^{2} \Delta t^{2}}\left[\left(u_{i+1}^{t+\Delta t}-2 u_{i}^{t+\Delta t}+u_{i-1}^{t+\Delta t}\right)-2\left(u_{i+1}^{t}-2 u_{i}^{t}+u_{i-1}^{t}\right)+\left(u_{i+1}^{t-\Delta t}-2 u_{i}^{t-\Delta t}+u_{i-1}^{t-\Delta t}\right)\right] \\
& +\frac{R^{2}}{C_{Q}^{2}} \frac{1}{\Delta t^{4}}\left[\left(u_{i}^{t+2 \Delta t}-2 u_{i}^{t+\Delta t}+u_{i}^{t}\right)-2\left(u_{i}^{t+\Delta t}-2 u_{i}^{t}+u_{i}^{t-\Delta t}\right)+\left(u_{i}^{t}-2 u_{i}^{t-\Delta t}+u_{i}^{t-2 \Delta t}\right)\right]=0 .
\end{aligned}
$$


Assuming a flexural wave $u=u_{0} e^{i(\omega t-k z)}$ propagating in the beam and substituting it into equation (A.10), we obtain

$$
\begin{aligned}
& \frac{1}{\Delta t^{2}}\left(e^{i \omega \Delta t}+e^{-i \omega \Delta t}-2\right)+\frac{C_{0}^{2} R^{2}}{h^{4}}\left(e^{-2 i k h}+e^{2 i k h}-4 e^{-i k h}-4 e^{i k h}+6\right) \\
& -\left(1+\frac{C_{0}^{2}}{C_{Q}^{2}}\right) \frac{R^{2}}{h^{2} \Delta t^{2}}\left(e^{i(\omega \Delta t-k h)}+e^{-i(\omega \Delta t-k h)}-2 e^{i \omega \Delta t}-2 e^{-i \omega \Delta t}+e^{i(\omega \Delta t+k h)}+e^{-i(\omega \Delta t+k h)}-2 e^{-i k h}-2 e^{i k h}+4\right) \\
& +\frac{R^{2}}{C_{Q}^{2} \Delta t^{4}}\left(e^{2 i \omega \Delta t}+e^{-2 i \omega \Delta t}-4 e^{i \omega \Delta t}-4 e^{-i \omega \Delta t}+6\right)=0 .
\end{aligned}
$$

Given $e^{i z}=\cos z+i \sin z$ and $e^{-i z}=\cos z-i \sin z$, equation (A.11) can be derived as

$$
\frac{4 C_{0}^{2} R^{2}}{h^{4}} \sin ^{4} \frac{k h}{2}-R^{2}\left(1+\frac{C_{0}^{2}}{C_{Q}^{2}}\right) \cdot \frac{4}{h^{2} \Delta t^{2}} \sin ^{2} \frac{\omega \Delta t}{2} \sin ^{2} \frac{k h}{2}+\frac{R^{2}}{C_{Q}^{2}} \frac{4}{\Delta t^{4}} \sin ^{4} \frac{\omega \Delta t}{2}-\frac{1}{\Delta t^{2}} \sin ^{2} \frac{\omega \Delta t}{2}=0 .
$$

Equation (A.12) is a quadratic equation with unknown $\sin ^{2}(\omega \Delta t / 2)$, and its solution can be obtained as follows:

$\sin ^{2} \frac{\omega \Delta t}{2}=\Delta t^{2} \frac{\left(\left(C_{0}^{2}+C_{Q}^{2}\right)\left(4 / h^{2}\right) \sin ^{2}(k h / 2)+\left(C_{Q}^{2} / R^{2}\right)\right) \pm \sqrt{\left(\left(C_{0}^{2}+C_{Q}^{2}\right)\left(4 / h^{2}\right) \sin ^{2}(k h / 2)+\left(C_{Q}^{2} / R^{2}\right)\right)^{2}-\left(\left(8 C_{0} C_{Q} / h^{2}\right) \sin ^{2}(k h / 2)\right)^{2}}}{8}$.

Given $\sin ^{2}(\omega \Delta t / 2) \leq 1$, the stability condition should be

$$
\Delta t^{2} \frac{\left(\left(C_{0}^{2}+C_{Q}^{2}\right) \cdot\left(4 / h^{2}\right) \sin ^{2}(k h / 2)+\left(C_{Q}^{2} / R^{2}\right)\right) \pm \sqrt{\left[\left(C_{0}^{2}+C_{Q}^{2}\right) \cdot\left(4 / h^{2}\right) \sin ^{2}(k h / 2)+\left(C_{Q}^{2} / R^{2}\right)\right]^{2}-\left[\left(8 C_{0} C_{Q} / h^{2}\right) \sin ^{2}(k h / 2)\right]^{2}}}{8} \leq 1
$$

which can be expressed approximately as

$$
\Delta t^{2} \frac{\left(C_{0}^{2}+C_{Q}^{2}\right) \cdot\left(4 / h^{2}\right) \sin ^{2}(k h / 2)+\left(C_{Q}^{2} / R^{2}\right)}{4} \leq 1 .
$$

That is,

$$
\begin{aligned}
\Delta t & \leq \frac{h}{\sqrt{\left(C_{0}^{2}+C_{Q}^{2}\right) \sin ^{2}(k h / 2)+\left(C_{Q}^{2} h^{2} / 4 R^{2}\right)}} \\
& \leq \frac{h}{\sqrt{\left(C_{0}^{2}+C_{Q}^{2}\right)+\left(C_{Q}^{2} h^{2} / 4 R^{2}\right)}} .
\end{aligned}
$$

A.2. Stability Condition for the Proposed Algorithm. The stability condition used in the proposed method can be provided by using equation (A.16) and the corresponding relations (i.e., equations (A.6)-(A.8)) as follows:

$$
\Delta t \leq \frac{h}{\sqrt{((\mathrm{EI}) h / J)+(12(\mathrm{EI}) / m h(1+2 \alpha))+(3(\mathrm{EI}) h / J(1+2 \alpha))}} .
$$

\section{B. Partial Calculation Results}

Table 7 shows the maximum earthquake tensile stresses, mean values, and standard deviations of different sections of the $150 \mathrm{~m}$ high chimney under 11 seismic waves when horizontal and vertical seismic accelerations are simultaneously inputted and vertical eccentricities are considered. The results when vertical eccentricities are ignored are shown in Table 8. 
Table 9 shows the maximum earthquake compressive stresses, mean values, and standard deviations of different sections of the $210 \mathrm{~m}$ high chimney under 11 seismic waves when horizontal and vertical seismic accelerations are simultaneously inputted and vertical eccentricities are considered. The results when vertical eccentricities are ignored are shown in Table 10.

Table 11 shows the maximum earthquake tensile stresses, mean values, and standard deviations of different sections of the $210 \mathrm{~m}$ high chimney under 11 seismic waves when horizontal and vertical seismic accelerations are simultaneously inputted and vertical eccentricities are considered. The results when vertical eccentricities are ignored are shown in Table 12.

In view vertical eccentricities, Table 13 shows the maximum earthquake compressive stresses, mean values, and standard deviations of different sections of the $150 \mathrm{~m}$ high chimney under 11 seismic waves when only horizontal seismic acceleration is inputted. Table 14 shows the results of maximum earthquake tensile stresses of the $150 \mathrm{~m}$ high chimney.

In view of vertical eccentricities, Table 15 shows the maximum earthquake compressive stresses, mean values, and standard deviations of different sections of $210 \mathrm{~m}$ chimney under 11 seismic waves when only horizontal seismic acceleration is inputted. Table 16 shows the results of the maximum earthquake tensile stresses of the $210 \mathrm{~m}$ high chimney.

\section{Data Availability}

The analysis result data used to support the findings of this study are included within the article. The calculation data used to support the findings of this study are available from the corresponding author upon request.

\section{Conflicts of Interest}

The authors declare that there are no conflicts of interest.

\section{Acknowledgments}

This study was supported in part by the National Natural Science Foundation of China (11672190 and 61673281), Liaoning Province Doctor Startup Fund (201601112), Liaoning Provincial Key Research and Development Program (2018103007), and Qinghai Provincial Key Research and Development Program (2017-NK-107).

\section{Supplementary Materials}

"Parameter data of $150 \mathrm{~m}$ reinforced concrete chimney.xlsx" is the RC chimney parameter data of $150 \mathrm{~m}$ height. "Parameter data of $210 \mathrm{~m}$ reinforced concrete chimney.xlsx" is the RC chimney parameter data of $210 \mathrm{~m}$ height. "Eleven kinds of earthquake records" are input data, which are used to study the seismic response of chimney structures. (Supplementary Materials)

\section{References}

[1] Z. P. Liao and F. Wang, "Vertical seismic motion input to structures," Earthquake Engineering and Engineering Vibration, vol. 3, no. 2, pp. 74-88, 1983, in Chinese.

[2] J. Liu and L. M. He, "Analysis of seismic response of chimneys to combined horizontal and vertical ground motion," Earthquake Engineering and Engineering Vibration, vol. 3, no. 2, pp. 89-98, 1983, in Chinese.

[3] F. Wang and Z. P. Liao, "Wave motion response of chimneys to vertical ground motions," China Civil Engineering Journal, vol. 17, no. 1, pp. 12-26, 1984, in Chinese.

[4] Q. Liu, R. Z. Zhou, and W. J. Yuan, "Computation of earthquake transient response of skyscraper structures and study of the dynamic properties," China Civil Engineering Journal, vol. 43, no. 5, pp. 63-69, 2010, in Chinese.

[5] S. Ding, Y. J. Wang, and S. J. Zhou, "Fracture test of chimney models subjected to vertical shock," Earthquake Engineering and Engineering Vibration, vol. 19, no. 3, pp. 34-36, 1999, in Chinese.

[6] J. Y. Chen, J. Zhou, and H. C. Ma, "Study on model test of highrise chimney subjected to vertical seismic action," Journal of Building Structures, vol. 26, no. 2, pp. 87-93, 2005, in Chinese.

[7] W. Huang, P. L. Gould, R. Martinez, and G. S. Johnson, "Nonlinear analysis of a collapsed reinforced concrete chimney," Earthquake Engineering \& Structural Dynamics, vol. 33, no. 4, pp. 485-498, 2004.

[8] P. L. Gould and W. Huang, "Higher mode effects in the nonlinear static analysis of a collapsed chimney," in Proceedings of the 2006 Structures Congress, vol. 2006, p. 19, St. Louis, MO, USA, May 2006.

[9] N. O. Akinci, "An investigation on seismic resistance of reinforced concrete industrial chimneys," in Proceedings of the 2009 Structures Congress, pp. 964-971, Austin, TX, USA, April 2009.

[10] W. Huang and P. L. Gould, "3-D pushover analysis of a collapsed reinforced concrete chimney," Finite Elements in Analysis and Design, vol. 43, no. 11-12, pp. 879-887, 2007.

[11] V. Lopes, J. M. Guedes, E. Paupério, A. Arêde, and A. Costa, "Ambient vibration testing and seismic analysis of a masonry chimney," Journal of Building Appraisal, vol. 5, no. 2, pp. 101-121, 2009.

[12] F. Minghini, G. Milani, and A. Tralli, "Seismic risk assessment of a $50 \mathrm{~m}$ high masonry chimney using advanced analysis techniques," Engineering Structures, vol. 69, pp. 255-270, 2014.

[13] C. Zhou, X. Zeng, Q. Pan, and B. Liu, "Seismic fragility assessment of a tall reinforced concrete chimney," The Structural Design of Tall and Special Buildings, vol. 24, no. 6, pp. 440-460, 2015.

[14] C. D. Zhou, X. L. Zeng, F. Zhao, and H. Zhou, "Seismic fragility analysis for high-rise reinforced concrete chimney," Earthquake Engineering and Engineering Dynamics, vol. 36, no. 2, pp. 173-181, 2016, in Chinese.

[15] C. D. Zhou, M. W. Tian, X. Zhang, P. G. Wang, and andX. Ma, "Seismic fragility analysis for high-rise RC chimney considering multi-dimensional seismic actions," China Civil Engineering Journal, vol. 50, no. 3, pp. 54-61, 2017, in Chinese.

[16] X. Chen, A. Q. Li, W. R. Cheng, and Y. Wang, "The Adomian decomposition method for dynamic characteristics of highrise buildings," Journal of Vibration Engineering, vol. 26, no. 4, pp. 493-499, 2013, in Chinese. 
[17] R. Sancibrian, I. Lombillo, E. G. Sarabia, Y. Boffill, H. Wong, and L. Villegas, "Dynamic identification and condition assessment of an old masonry chimney by using modal testing," Procedia Engineering, vol. 199, pp. 3410-3415, 2017.

[18] T. Tatara and B. Ratajewicz, "The selection of a dynamic model of a RC chimney based on in Situ research," in Proceedings of the International Conference on Experimental Vibration Analysis for Civil Engineering Structures, pp. 619630, San Diego, CA, USA, July 2017.

[19] D. Mehta and N. J. Gandhi, "Time response study of tall chimneys under the effect of soil structure interaction and long period earthquake impulse," in Proceedings of the 14th World Conference on Earthquake Engineering, Beijing, China, October 2008.

[20] R. Livaoglu, "The numerical and empirical evaluation of chimneys considering soil structure interaction and hightemperature effects," Soil Dynamics and Earthquake Engineering, vol. 66, pp. 178-190, 2014.

[21] A. M. Halabian and S. Kabiri, "Effect of foundation flexibility on ductility reduction factors for R/C stack-like structures," Earthquake Engineering and Engineering Vibration, vol. 10, no. 2, pp. 277-290, 2011.

[22] S. V. Jisha, B. R. Jayalekshmi, and R. Shivashankar, “3D soilstructure interaction analyses of annular raft foundation of tall RC chimneys under wind load," Indian Geotechnical Journal, vol. 44, no. 4, pp. 409-426, 2014.

[23] B. R. Jayalekshmi, S. V. Jisha, and R. Shivashankar, "Analysis of foundation of tall $\mathrm{R} / \mathrm{C}$ chimney incorporating flexibility of soil," Journal of the Institution of Engineers (India): Series A, vol. 98, no. 3, pp. 211-217, 2017.

[24] C. D. Zhou, X. L. Zeng, J. Chen, and B. Liu, "Seismic collapse resistance analysis of tall reinforced concrete chimney," Engineering Mechanics, vol. 33, no. 5, pp. 57-65, 2016, in Chinese.

[25] C. D. Zhou, X. L. Zeng, and Q. L. Pan, "Seismic response analysis of high-rise RC chimney including soil-structure interaction," Earthquake Engineering and Engineering Dynamics, vol. 36, no. 3, pp. 140-150, 2016, in Chinese.

[26] R. Sarkar, D. Shrimal, and S. Goyal, "Seismic analysis of a $275 \mathrm{~m}$ tall RCC multi-flue chimney: a comparison of IS code provisions and numerical approaches," Advances in Structural Engineering, vol. 2, pp. 1015-1025, 2015.

[27] J. L. Wilson, "Earthquake response of tall reinforced concrete chimneys," Engineering Structures, vol. 25, no. 1, pp. 11-24, 2003.

[28] H. Q. Liu, W. B. Li, R. Y. Wu, and L. F. Yan, "Elastic-plastic seismic response analysis on the special-shaped chimney," Applied Mechanics and Materials, vol. 711, pp. 520-524, 2014.

[29] N. S. Abhyankar, "Flexural waves in beams with geometrical and material longitudinal discontinuities," International Journal of Impact Engineering, vol. 9, no. 2, pp. 205-222, 1990.

[30] Information on https://ngawest2.berkeley.edu/, Peer Ground Motion Database, Pacific Earthquake Engineering Research Center.

[31] GB50010-2010, Code for Seismic Design of Buildings, China Architecture \& Building Press, Beijing, China, 2010.

[32] China Architecture \& Building Press, Design Manual of Chimneys, China Architecture \& Building Press, Beijing, China, 1989.

[33] GB50010-2010, Code for Design of Concrete Structures, China Architecture \& Building Press, Beijing, China, 2015. 